RÖMISCHE HISTORISCHE MITTEILUNGEN, 47. Band/2005, 227-278

(C) by Österreichische Akademie der Wissenschaften, Wien

Christina STRUNCK

\title{
Bernini zitiert sich selbst? Die Kunstmöbel der Galleria Colonna in Rom*
}

\author{
Mit 18 Abbildungen
}

Nicht anders als heute gehörte es auch schon vor drei Jahrhunderten zum Metier des Fremdenführers, seine Klientel durch reißerische Geschichten bei Laune zu halten. So berichtete Johann Balthasar Klaute von seiner Besichtigung des Palazzo Colonna: Noch in einem anderen Gemach ist ein schön Cabinet, so König Carolus II. in Engelland gehabt, und der Connétable Colonna von einem Englischen Kauffmann vor 11.000 scudi erkauft haben soll; Gegen welchem gleich über noch ein anders von Ebenholtz, mit über alle massen kunstreichen bas-reliefs aus Elffenbein gezieret, zu sehen ist. Wobey uns erzehlet worden, dass zween Brüder aus Teutschland hieran gearbeitet, einer aber den andern bey entstandenen Zwistigkeiten entleibet, und darauf um der straffe zu entgehen, das Reiß-aus genommen hätte, so dass diese sehr delicate arbeit völlig nicht ausgemacht worden ${ }^{1}$. Eine abenteuerliche Moritat - doch mit wahrem Kern, wie sich noch zeigen wird.

* Bei dem vorliegenden Text, der ab 24. März 2004 auf http://colosseum.biblhertz.it/ werkstatt/frameset.htm zur Diskussion gestellt wurde, handelt es sich um das Unterkapitel 6.6. der im November 2000 an der FU Berlin eingereichten Dissertation der Autorin mit dem Titel „Berninis unbekanntes Meisterwerk. Architektur und Programm der Galleria Colonna in Rom (1661-1700)“. Einige der im Folgenden vorgestellten Dokumente hat unabhängig davon auch Natalia Gozzano gefunden und sie im Anhang ihrer im Juni 2004 erschienenen Dissertation präsentiert, ohne sie jedoch zu kommentieren: N. Gozzano, La quadreria di Lorenzo Onofrio Colonna. Prestigio nobiliare e collezionismo nella Roma barocca. Roma 2004, 242-245, 251-253. Soweit nicht anders spezifiziert, befinden sich die zitierten Dokumente im Archivio Colonna (Subiaco). Für ihr freundliches Entgegenkommen und vielfältige Hilfestellungen bei den langjährigen Forschungen in diesem Archiv sei insbesondere Piero Scatizzi, Don Romano und Elia Mariano gedankt.

1 Klaute besichtigte den Palazzo Colonna am 8. Februar 1700; die Beschreibung erschien jedoch mit etlicher Verspätung: J. B. KLaute, Diarium Italicum, oder 


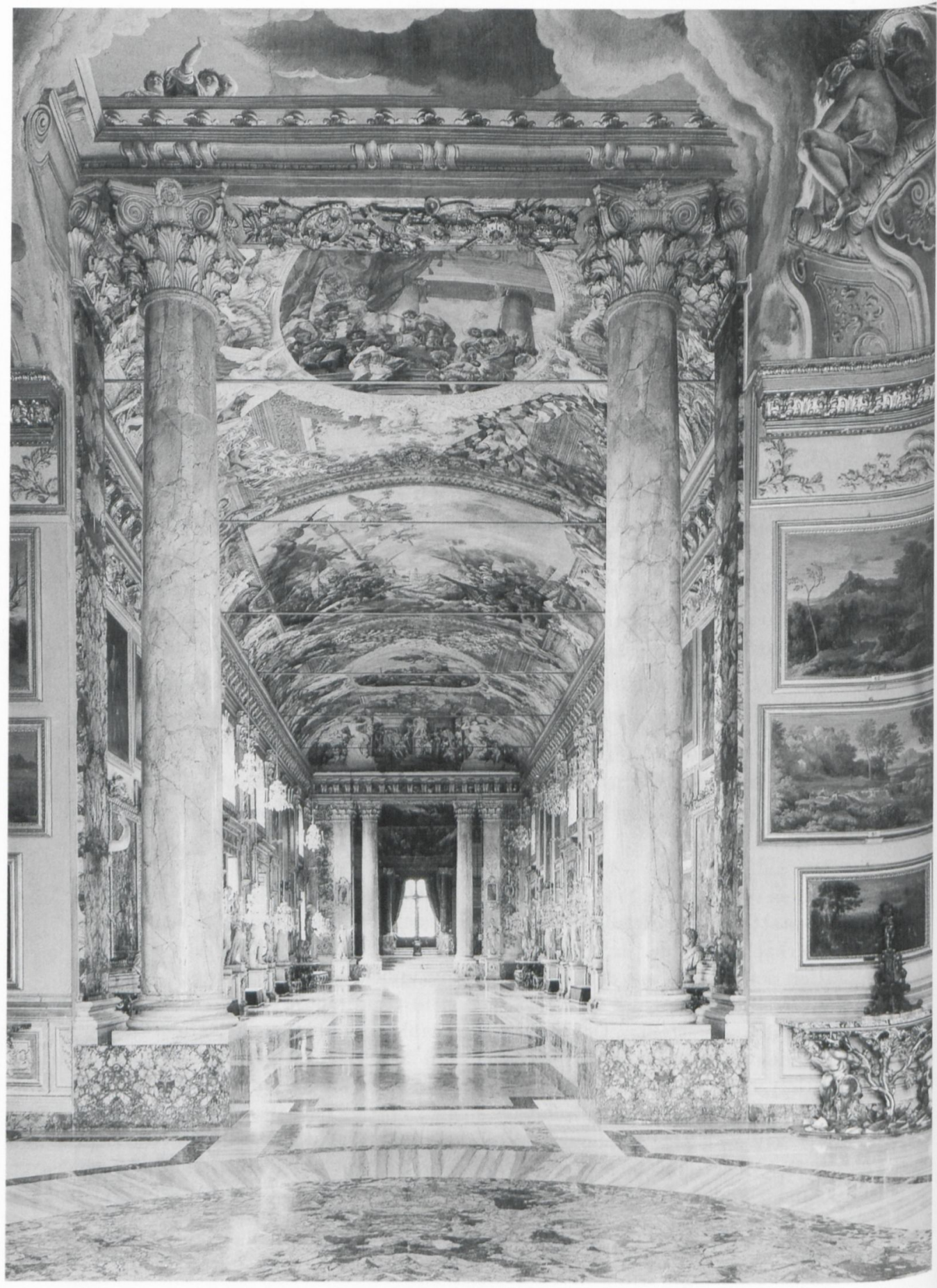

Abb. 1: Rom, Galleria Colonna, Blick von Westen nach Osten 
Bei Klautes Palastbesuch am 8. Februar 1700 standen die beiden genannten Schränke im westlichen Vorraum der Galleria Colonna ${ }^{2}$, die nach knapp vierzigjähriger Bauzeit damals ihrer Vollendung entgegenstrebte $^{3}$. Unschwer ließ sich die Ambition des Bauherren erkennen, den prächtigsten privaten Galerieraum Roms zu schaffen: Die durch Deckenfresken, vergoldeten Stuck und Buntmarmor-Inkrustationen farbig reich akzentuierte Monumentalarchitektur fasste eine erlesene Sammlung von Gemälden und antiken Skulpturen (Abb. 1). Selbstverständlich hatte sich auch die Möblierung an diesem hohen Anspruchsniveau auszurichten.

Aufgrund neu entdeckter Rechnungen und Briefe lassen sich die Kunstmöbel der Galleria Colonna, die bereits verschiedentlich das Interesse der Forschung gefunden haben ${ }^{4}$, nun präziser als bisher in ihrer

Beschreibung derjenigen Reyse, welche der Durchläuchtigste Fürst und Herr, Herr Karl, Landgraf von Hessen ... am 5. Tag Dec. st. v. Anno 1699, unterm Segen Gottes aus hiesiger Dero Fürstlicher Residenz angetreten ... . Cassel 1722, hier 142. Zu Klaute siehe auch F. NoAcK, Das Deutschtum in Rom seit dem Anfang des Mittelalters. Stuttgart u. a. 1927, II, 315.

${ }^{2}$ Siehe unten Anm. 69. Ein Inventar von 1714 beschreibt gegenüber dem mit Elfenbeinreliefs gezierten Schrank (Abb. 2) ein Möbel, das mit dem laut Klaute aus dem Besitz Karls II, stammenden Schrank identisch sein dürfte: E. A. SAFARIK-C. PUJA, Collezione dei dipinti Colonna. Inventari 1611-1795 (The Provenance Index del Getty Art History Information Program, Inventari Italiani 2). München u. a. 1996, 283, Nr. 562.

${ }^{3}$ Zur Baugeschichte der Galerie siehe C. Strunck, Lorenzo Onofrio Colonna, der römische Sonnenkönig. Neue Dokumentenfunde zu Bernini und seinem Kreis im Archivio Colonna. Zeitschrift für Kunstgeschichte 61 (1998), 568-577. C. STrunck, Le chef d'œuvre inconnu du Bernin: La galerie Colonna, Fischer von Erlach et un possible séjour romain de Jules Hardouin-Mansart, in: Le Bernin et l'Europe du baroque triomphant à l'age romantique, hrsg. von C. Grell-M. Stanic. Paris 2002, 391-409.

${ }^{4}$ Italienische Künstlerbriefe aus der Barockzeit. Hrsg. und erläutert von Oskar POLLAK. Jahrbuch der königlich preußischen Kunstsammlungen, Beiheft zum 34. Band (1913), 1-77, hier 16-18; E. Coudenhove-Erthal, Carlo Fontana und die Architektur des römischen Spätbarocks. Wien 1930, 50; G. Lizzani, Il mobile romano. Milano 1970, 130-132, Kat.-Nr. 219, 220; A. Gonzalez-Palacios, Il Tempio del Gusto. Le arti decorative in Italia fra classicismi e barocco. Roma e il Regno delle due Sicilie I. Milano 1984, 38, 64, 77, 96; Fasto romano. Dipinti, sculture, arredi dai Palazzi di Roma, hrsg. von A. Gonzalez-PAlacios. Roma 1991, 108f.; A. Negro, Guide rionali di Roma. Rione II, Trevi, parte ottava. Roma 1997, 52-55; R. VAleriani, scheda in: Gian Lorenzo Bernini. Regista del Baroceo, hrsg. von M. G. Bernardini-M. Fagiolo dell'Arco. Milano 1999, 408f.; E. A. Safarik, Palazzo Colonna. Con i contributi di M. G. Picozzi e R. Valeriani. Roma 1999, 256f.; M. ÒLIN, La scultura romana del Settecento nei disegni del Museo Nazio- 
Entstehung begreifen. Es lohnt sich, dieses Material hier auszubreiten, da es nicht nur einen außergewöhnlich lebhaften Einblick in die Praxis barocken Kunstschaffens gewährt, sondern auch neue Impulse für Datierung und Zuschreibung der betreffenden Werke gibt. Während im ersten Teil des Textes die Dokumente zu den verschiedenen Objekten gesichtet und kommentiert werden sollen, konzentrieren sich der zweite und dritte Abschnitt auf das schon von Johann Balthasar Klaute zu Recht bewunderte Prunkstück, den mit Elfenbeinreliefs geschmückten Kabinettschrank (Abb. 2), ein Meisterwerk barocken Kunsthandwerks. Es gilt, die Themen und Vorbilder der einzelnen Reliefs erstmals zu identifizieren, das Bildprogramm zu interpretieren und die traditionelle Zuschreibung des Projekts an Carlo Fontana kritisch zu überprüfen: Etliche Indizien deuten darauf hin, dass bei diesem ungewöhnlichen Entwurf Bernini höchstpersönlich eine Hand im Spiel gehabt haben könnte.

Oskar Pollaks „Italienische Künstlerbriefe aus der Barockzeit“ von 1913 bilden die Grundlage, auf der alle späteren Publikationen den reliefierten Kabinettschrank (Abb. 2) in die Jahre 1678-1680 datieren und Carlo Fontana zuweisen ${ }^{5}$. Die drei diesbezüglichen von Pollak veröffentlichten Briefe stammen vom 15. September 1678, 18. Februar 1679 und 12. Juli $1680^{6}$, d. h. aus jenem Zeitraum, in dem sich der Auftraggeber Principe Lorenzo Onofrio Colonna als Vizekönig von Aragon in Spanien aufhielt ${ }^{7}$. Die intensive Korrespondenz, die er während seiner Abwesenheit mit dem in Rom verbliebenen maggiordomo Maurizio Bologna führte, enthält zahlreiche weitere Passagen über den Fortgang der Arbeiten $^{8}$. Mit Lorenzo Onofrios Rückkehr nach Rom brechen diese Mitteilungen naturgemäß ab. Als wichtige dokumentarische Ergänzung

nale di Stoccolma, in: Sculture romane del Settecento II. La professione dello scultore, hrsg. von E. Debenedettr. Roma 2002, 7-22, hier 12, 15 (Anm. 30), $21 f$.

${ }^{5}$ Siehe die in Anm. 4 genannten Publikationen.

${ }^{6}$ Dokument 2, 5, 15.

${ }^{7}$ Zum Spanienaufenthalt Lorenzo Onofrio Colonnas (1678-1681) vgl. E. TAuBuriNI, Due teatri per il principe. Studi sulla committenza teatrale di Lorenzo Onofrio Colonna (1659-1689). Con un'ipotesi di ricostruzione del teatro „piccolo” elaborata in collaborazione con Sergio Rotondi. Roma1997, 66-71.

8 Die Funktion des Maurizio (bzw. nach seiner eigenen Schreibweise Mauritio) Bologna als maggiordomo geht aus der umfangreichen Korrespondenz hervor, von der im Folgenden nur ein kleiner Teil ausgewertet werden kann. Zu den Aufgaben 


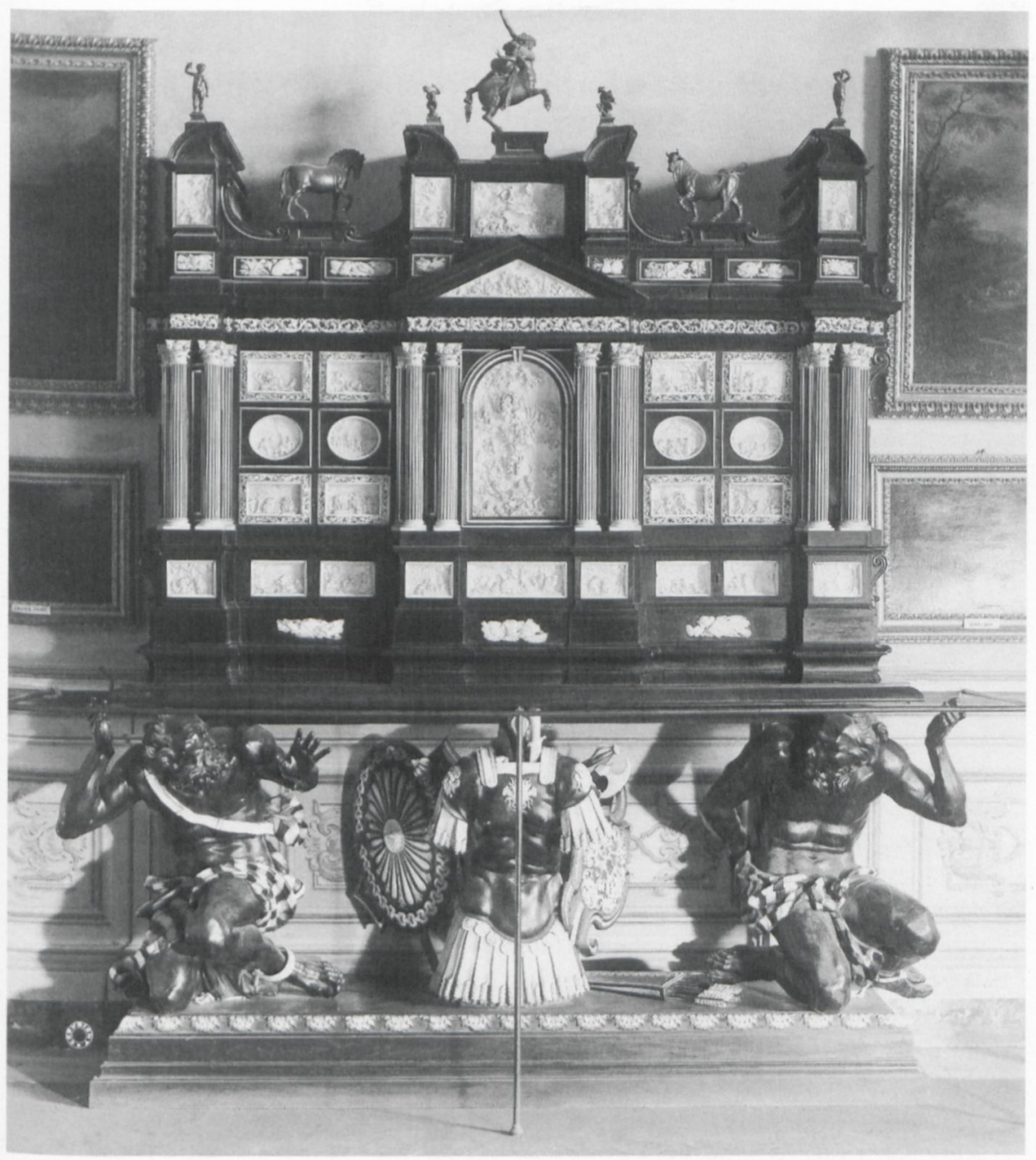

Abb. 2: Rom, Galleria Colonna, Kabinettschrank mit Elfenbeinreliefs der Gebrüder Stainhart (sogenanntes studiolo d'avorio).

Die Themen der Reliefs (jeweils von links nach rechts)

Oberste Reihe: Martyrium des HI. Sebastian, Anbetung der Hirten, Auferstehung,

Vision des Konstantin, Zurückweisung Attilas durch Leo den Großen.

Giebelfeld: Bethlehemitischer Kindermord. Zentralrelief: Jüngstes Gericht. Zweite Reihe von oben: Reiterschlacht, Jagdszene,

Einzug in die Arche Noah, Reiterschlacht.

Dritte Reihe (Medaillons): Antiochus und Stratonice, Artemisia mit dem Projekt des „Mausoleion“, Cyrus und Panthea, Antike Opferszene (Die eherne Schlange?). Vierte Reihe von oben: Die Enthaltsamkeit des Scipio, Coriolan und seine Familie,

Reiterschlacht, Sündenfall.

Unterste Reihe: Augustus und Cleopatra, Reiterschlacht, Bekehrung Pauli,

Antiochus III. und die Priesterin der Diana, Kreuztragung, Alexander und die Frauen des Darius, Der Hl. Eustachius in der Löwengrube,

Erschaffung Evas, Erschaffung der Tiere. 
müssen daher die Handwerkerrechnungen herangezogen werden, die belegen, was vor bzw. nach der Spanienreise geschah.

Wie aus einer Rechnung des Ebenista Giacomo Herman hervorgeht, wurde spätestens ab dem 24. April 1675 kontinuierlich an den Elfenbeinreliefs für ein studiolo grande gearbeitet ${ }^{9}$. Die Konzeption des Projekts ist daher erheblich früher als bisher vermutet anzusetzen und fällt genau in jenes Jahr, in dem auch der von Bernini initiierte Umbau der Galleria Colonna begann ${ }^{10}$. Die. Namen der ausführenden Bildschnitzer werden in dem Dokument nicht genannt, doch dürften damals bereits die aus Weilheim stammenden Brüder Franz und Dominik Stainhart am Werk gewesen sein, die sich seit 1674 oder Anfang 1675 in Rom aufhielten und bis 1680 für den Schrank verantwortlich waren ${ }^{11}$. Im September 1675 wurden sie mit einem regelmäßigen Monatsgehalt von 22 scudi in den Colonna-Haushalt aufgenommen; die Stati d'Anime sowie ein Raumplan (Abb. 3) belegen, dass sie im Palazzo Colonna wohnten ${ }^{12}$.

eines maggiordomo vgl. P. WADDy, Seventeenth-Century Roman Palaces. Use and the Art of the Plan. New York-Cambridge 1990, 31f. und M. VöLKEL, Römische Kardinalshaushalte des 17. Jahrhunderts. Borghese-Barberini-Chigi. Tübingen 1993, 187-190.

${ }^{9}$ Dokument 1; die Fortsetzung dieser Arbeiten (u. a. Zersägen und Anbringen des Elfenbeins) dokumentiert eine weitere Rechnung Giacomo Hermans ab 18. September 1677 (in I. A. 62). Herman (ca. 1615-1685) war ein begehrter Spezialist auf seinem Gebiet, der zwischen 1654 und 1677 für den päpstlichen Hof arbeitete: siehe Noack (wie in Anm. 1), I, 83, 746 und II, 256; González-Palactos, Il Tempio (wie in Anm. 4), I, 28, 60f. und II, 64; A. Werland, Der Campo Santo Teutonico in Rom und seine Grabdenkmäler. Roma-Freiburg-Wien 1988, 269 271, 771-773; Il Palazzo del Quirinale, hrsg. von F. Borsi. Rom 1991, 154.

${ }^{10}$ Strunck, Lorenzo Onofrio Colonna (wie in Anm. 3), 572.

11 K. Feuchtmayr, Dominicus Stainhart, in: Thieme-Becker 31 (1937), 450-451; DERs., Franz I Stainhart, in: ebd., 451. Die bereits von Feuchtmayr vertretene Datierung des Romaufenthalts in die Jahre 1674-1680 wird bestätigt durch die Dokumente 13 und 14, welche die Abreise aus Rom für Sommer 1680 sichern. Da die Stainharts nach eigener Aussage sechs Jahre in Rom verbracht hatten, müssen sie 1674 oder Anfang 1675 dort eingetroffen sein (vgl. Feuchtмayr, 450). Zum Euvre der Gebrüder Stainhart siehe neuerdings auch H.-U. KEssler, Die Elfenbeinreliefs aus der Werkstatt der Gebrüder Stainhart, in: Elfenbein, Alabaster und Porzellan aus der Sammlung des fürstbischöflichen Ministers Ferdinand von Plettenberg und der Freiherren von Ketteler (Patrimonia 193). Berlin 2001, 47-73.

${ }^{12}$ In der Rubrik Diversi des Rollo della Famiglia sind ab September 1675 monatliche Zahlungen von 22 seudi an die Bildhauer dokumentiert, die zuerst als Fran ${ }^{c o} e$ Dom. ${ }^{c o}$ Stanthete Todeschi Intagliatori, dann als Francesco e Domenico Stontechen Intagliatori Todeschi o Scultori und schließlich als Francesco, et Domenico Scultori Todeschi bezeichnet werden (Archivio Segreto Vaticano, Fondo Colonna, busta 34; 

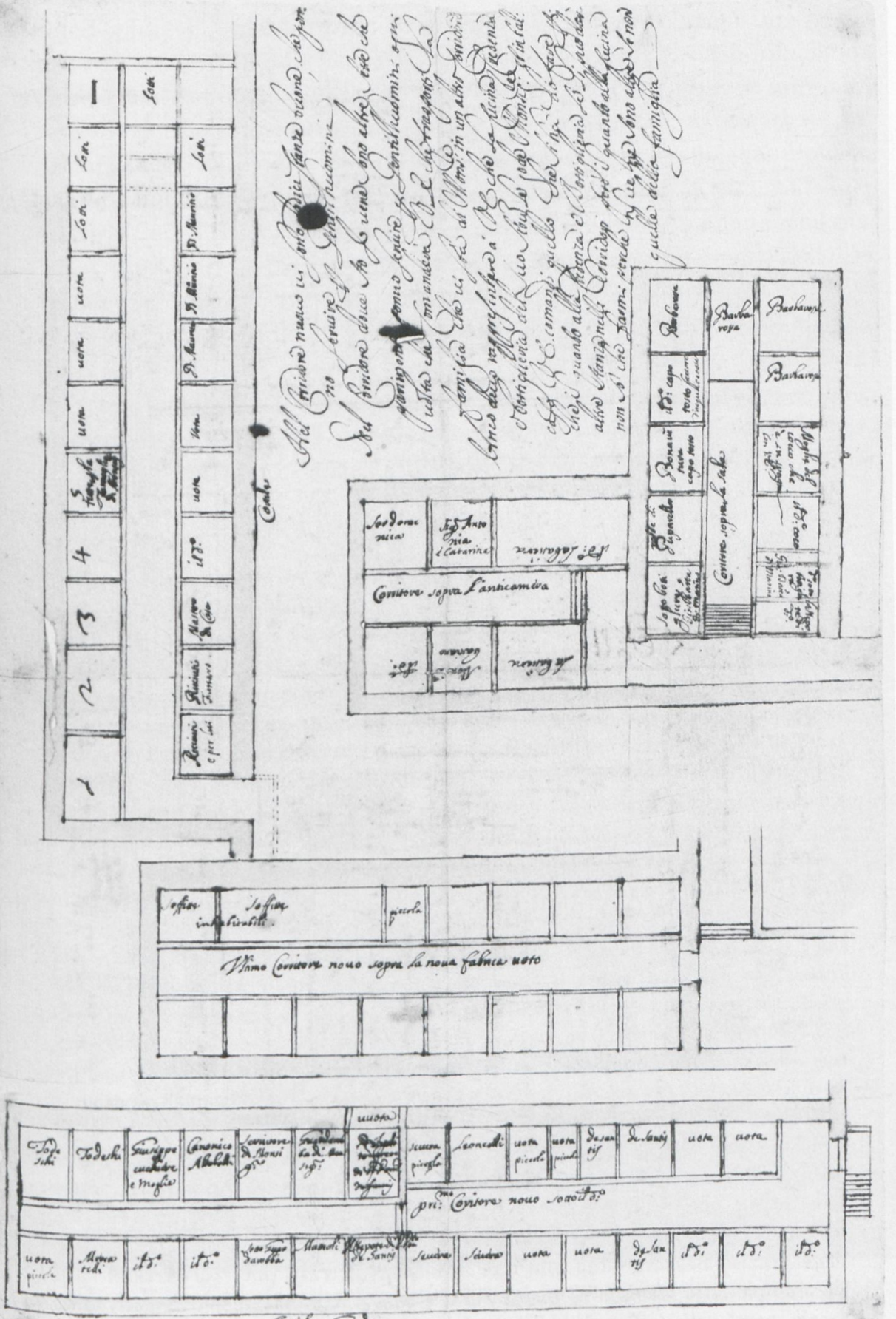

Covite smerde 
Die Stainharts selbst bestätigten brieflich, dem Principe Colonna schon vor seiner Abreise nach Spanien (d. h. vor Juli 1678) einige Schnitzereien für den Schrank gezeigt zu haben: Sie wendeten sich an l'Eccellenza Sua come Signore, che con l'occhio del suo rettissimo, e purgatissimo giuditio avanti la partenza in vedere alcuni pezzi già fatti ne diede segno di gradimento $^{13}$. Zu jenem Zeitpunkt waren offenbar sogar bereits die meisten Reliefs fertig - das lässt sich nicht nur aus einigen Briefen ablesen ${ }^{14}$, sondern auch aus einer Rechnung, die im Dezember 1677 die Verglasung etlicher Elfenbein-Schnitzereien vermerkte ${ }^{15}$.

1678 erhielten die Gebrüder Stainhart die zusätzliche Aufgabe, den Fuß des sogenannten studiolo gioiellato (Abb. 4) zu gestalten. Im Januar des Jahres hatte der Principe Colonna von Lorenzo Paribeni jenes Prunkmöbel erworben, das in den Quellen auch als studiolo di gioie e pietre oder studiolo pretioso bezeichnet wird, da es mit Pietra-dura-Arbeiten und Säulen aus Amethyst geschmückt ist ${ }^{16}$. Es kostete Lorenzo Onofrio neben

vgl. unten Anm. 30). In den Stati d'anime von 1678 figurieren unter den Bewohnern des Palazzo Colonna Francesco et Domenico Stontechet Intagliatore Todescho (Archivio del Vicariato, SS. Apostoli, Stati d'anime 53, Nr. 270, fol. 188ff., Rubrik Diverse). Die eigenhändigen Schriftzeugnisse der beiden Bildschnitzer verbinden hingegen die italianisierten Vornamen Francesco (Franz) und Domenico (Dominik) mit der Namensform Stainart bzw. Stainardi (siehe unten Anm. 43 und Dok. 13). Einem Raumplan von 1679 zufolge hatten die Todeschi zwei Zimmer in dem beim Cortile Grande gelegenen Flügel inne (Abb. 3 unten links). Die heute separat archivierte Zeichnung (III. QB. 4, Nr. 2) lag höchstwahrscheinlich einst einem Brief Maurizio Bolognas vom 1. Oktober 1679 bei, denn darin heißt es: ... Li Corridori son finiti et ultimamente ho fatto perfettionare le fenestre, e porte et ogni cosa è pronto per habitarvi per quando con la gratia di Dio, Vostra Eccellenza venghi con salute che del continuo supplico Sua Divina Maestà me lo porti presto per buon governo delli suoi stati. E perciò accludo a Vostra Eccellenza la pianta di tutti li corridori, che sono in questo Palazzo con il nome di quelli che hoggi vi dimorano a finche sappia le stanze che restano vuote per accomodar la famiglia che è in Spagna; e prima che questa arrivi qui possa Vostra Eccellenza destinare in tempo le Camere che ad ognuno comanderà dare ... . (Carteggio L. O. Colonna 1679, camicia 238.)

13 Dokument 13. Lorenzo Onofrio Colonna brach im Juli 1678 nach Spanien auf: vgl. I. AF. 33, fol. 1.

${ }_{14}$ Dokument 2, 5, 6, 14 .

${ }^{15}$ Glaserrechnung ab 11. August 1677 (in I. A. 80): im Dezember 1677 Lieferung von Glasscheiben, u. a. per haver messi numero 27 cristalli bianchi alli intagli d'avolio consegnato all'ebanista disse per il studiolo grande.

${ }^{16}$ Eine präzise Beschreibung gibt das Inventar von 1714 (hier verkürzend zitiert): un studiolo tutto lavorato dj pietra dura, e vasi à fogliami, e spartimentij tanto in faccia, come nelle teste con dodici colonne d'Amatistà alte l'una palmi uno, et onze due, e mezzo ... con sua balaustrata simile sopra li finimentij con otto piastrelli ...e 


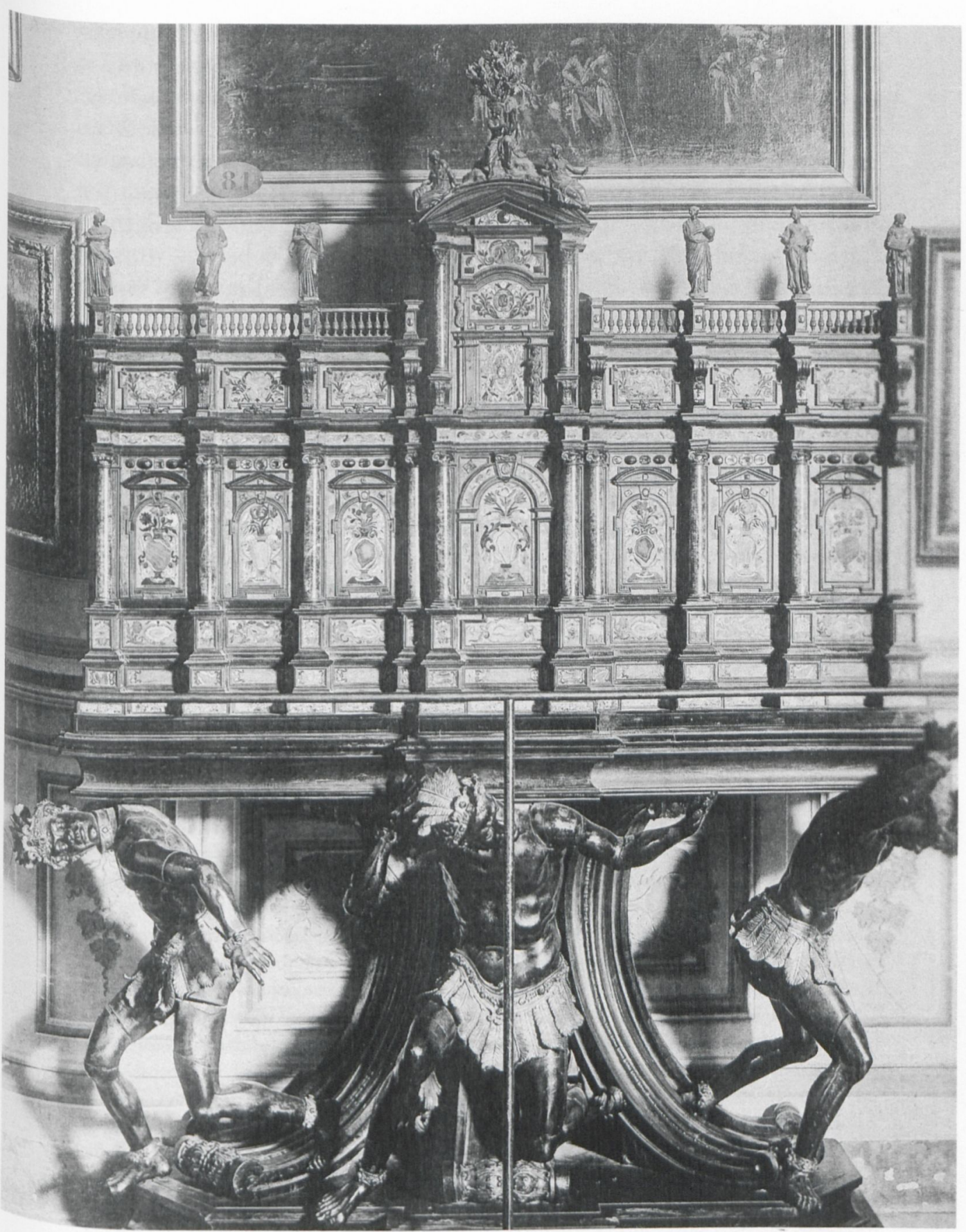

Abb. 4: Rom, Galleria Colonna, Kunstschrank (sogenanntes studiolo gioiellato) 
einer Leibrente für den Abt Angelo Lana (der günstigerweise wenig später verstarb) stolze 2700 scudi, die teils bar, teils in Wertgegenständen gezahlt wurden - u. a. wechselten in diesem Kontext Gemälde von Francesco Albani und Guido Reni den Besitzer ${ }^{17}$.

$\mathrm{Zu}$ einem nicht genau bestimmbaren Zeitpunkt vor dem 26. August 1678 entwarf ein Signor Filippo Architetto für den fertig gekauften Schrank einen neuen Untersatz, dessen tragende Konstruktion Giacomo Herman ausführte $^{18}$, während die Stainharts bis September die stützenden Figuren schufen ${ }^{19}$. Bei dem genannten Architekten handelte es sich um Philipp Schor, heute vor allem bekannt als Lehrmeister des jungen Johann Bernhard Fischer (,von Erlach') ${ }^{20}$, Sohn des damals hoch ge-

sopra li sudetti pilastrelli sei figure d'argento dorato che rappresentano le nove muse ... e sopra il frontespizio Orfeo in figura sotto un albero che suona la Lira con due altre figure rappresentatij due muse una per parte tutta d'argento dorato ... longo detto studiolo palmi sette, et onze undici, et alto nel maggiore palmi cinque con suo piede sotto ... con tre schiavi con ornamento in centura dj penne dj metallo dorato et il simile in testa, et anche le maniglie alli piedj, e mano tutto gioiellato ... il suddetto piede dj pero nero. Safarik-PUJA (wie in Anm. 2), 281f., Nr. 543. Zur Lokalisierung des Schrankes (die möglicherweise nicht den ursprünglichen Intentionen entsprach, da der Auftraggeber Lorenzo Onofrio Colonna 1689 lange vor Einrichtung der Galerie verstorben war) siehe unten Anm. 69.

${ }_{17}$ Zahlungsanweisung an Nicolò Foresta zur Zahlung von scudi 50 an Lorenzo Paribeni als Abschlusszahlung für das Studiolo di gioie e pietre (in I. A. 54): Nicolò Foresta pagate al Sig. Lorenzo Paribeni scudi cinquanta moneta suo rimborzo d'altra tanta somma da esso fatta pagare al quondam Sig. Abbate Angelo Lana per il trimestre anticipato dell'annuo vitalitio di scudi 200 simili dovuto al detto quondam Abbate Lana sua vita durante, in parte del prezzo dello studiolo di gioie, e pietre, e da noi accollato nella compra del detto studiolo, come per istromento rogato per l'atti del Paccichelli Not(aio) di Campidoglio sotto li 7 gennaro prossimo ... Essendo vacato detto vitalitio dopo a nostro favore per la morte del detto Abbate Lana, seguita li 11 del corrente mese di marzo, e restando il detto Signor Lorenzo intieramente sodisfatto di tutto il prezzo del detto studiolo stante il pagamento fattogli di altri scudi cinquecento in contanti, di altri scudi millecento in tanti argenti, d'altri scudi seicento in due quadri, uno di Guido, l'altro dell'Albano, e delli restanti scudi cinquecento in due studioli, consegnatogli il tutto a sua sodisfatione.

18 Eine Rechnung von Giacomo Herman über Arbeiten ab 18. September 1677 (in I. A. 62) vermerkt unter dem Datum 26. August 1678: mi fu ordinato un piede di Ebano, che serviva per il Studiolo bello di pietre ... fatto sopra il disegno del Sig. Filippo Architteto (scudi 25:00). Außerdem restaurierte Herman das Studiolo bello di gioie dov'erano scollati molti pezzi di Cornici d'Ebano, wofür er 10 scudi berechnete.

19 Dokument 2.

${ }^{20}$ Fischer kam ca. 1670/71 nach Rom und fand speziell wegen seiner skulpturalen Ausbildung in der Schor-Werkstatt Aufnahme: Es kame nemblich obgemelter Herr 
schätzten Innsbrucker, Dekorationsingenieurs' Johann Paul Schor ${ }^{21}$. Als Berater wurde der Marchese T(h)eodoli hinzugezogen, auf dessen guten Geschmack der Principe Colonna offenbar viel gab ${ }^{22}$. Da das betreffende Möbelstück heute dem Elfenbein-Schrank gegenüber steht, beide einen vergleichbaren neuen Unterbau aus hölzernen Mohren erhielten und zeitgleich von denselben Kunsthandwerkern bearbeitet wurden, lässt sich vermuten, dass sie von Anfang an als Pendants gedacht waren.

Als die einzelnen Teile des piede Anfang 1680 zusammengefügt werden sollten, stellte sich heraus, dass sich die Mohren nicht entsprechend der Zeichnung einfügen ließen, si che è stato necessario di nuovo a guastarli et aggiustarli con gran fatica, e travaglio con il parere di Filippo Schor, et altri periti in quest'arte ${ }^{23}$. Schor quittierte daher im März Zahlungen

$V$ Erlach in seiner jugendt als ein Bildhauer nacher Rom, konnte aber unter denen Romanischen Bildhauern sein Convenientz nit finden, da wurd ihme gerathen, sich beim H: Philippen Schor zu melden als welcher sehr Villes zu Thun habe, und deßentwegen unter andern auch einen bei sich zu halten pflegte so mit der Bildhauerey und $\beta$ [sic] und absonderlich mit poßiren [bossieren)] umgehen konte, um dadurch seine Verzierungs inventionen in modellen fürstellen zu können. wo mit dann der fürtreffliche geist des H: V Erlach zu gleich auch sich die Architectur bekant macht. J. F. Scнов, Alerhand Bau und Kunstschrift (1751). Innsbruck, Universitätsbibliothek, Cod. MS 856, zitiert bei H. Sedlanar, Johann Bernhard Fischer von Erlach, Wien ${ }^{2} 1976$, 359. Siehe auch E. SLADEK, Der Italienaufenthalt Johann Bernhard Fischers zwischen 1670/71 und 1686. Ausbildung-Auftraggeber-erste Tätigkeit, in: Fischer von Erlach und die Wiener Barocktradition, hrsg. von F. Polleross. Wien-Köln-Weimar 1995, 147-176.

${ }^{21}$ Grundlegend zu den Schor: P. M. Ehrucre, Giovanni Paolo Schor, Diss. Columbia University 1975; P. Werkner, Johannes Paul Schor als römischer „Dekorationsingenieur". Alte und moderne Kunst 25 (1980), Heft 169, 20-28; P. Werkner, Zeichnungen von Johannes Paul Schor in der Königlichen Sammlung in Windsor Castle. Pantheon 40 (1982), 39-45; G. Fusconi, Disegni decorativi di Johann Paul Schor. Bollettino d'arte 70 (1985), Nr. 33-34, 159-180; DIEs., Disegni decorativi del baroceo romano. Roma 1986; A. CAPPELlIERI, Filippo e Cristoforo Schor, „Regi Architetti e Ingegneri” alla Corte di Napoli, in: Capolavori in festa. Effimero baroceo a Largo di Palazzo (1683-1759). Napoli 1997, 73-89. Neue Dokumente zu den Arbeiten, die Johann Paul und Philipp Schor im Palazzo Colonna ausführten, bei C. STrunck, Berninis unbekanntes Meisterwerk. Architektur und Programm der Galleria Colonna in Rom (1661-1700), Diss. FU Berlin 2000; eine neue Gesamtschau des Schor'schen Euvres in: Ein Regisseur des barocken Welttheaters. Johann Paul Schor und die internationale Sprache des Barock, hrsg. von C. STRunck (erscheint 2006).

${ }^{22}$ Dokument 3 und 4. Zu Theodoli siehe Gozzano (wie in Anm. *), 93.

${ }^{23}$ Dokument 12. 
für das Überarbeiten und Restaurieren der Figuren ${ }^{24}$. Anschließend garnierte der Juwelier Camillo del Ponte die Mohren mit Edelmetallen und Schmucksteinen ${ }^{25}$; wiederum zeichnete Schor dafür verantwortlich ${ }^{26}$. Die Zahlungen gehen bis 1681 weiter ${ }^{27}$, doch meldete Maurizio Bologna bereits am 10. November 1680 reichlich entnervt die Vollendung: Per gratia di Dio mi vedo già libero con haver terminato il piede dello studiolo gioiellato, e postolo sù con haverlo fatto pulire, e raggiustare in modo che credo sarà di gusto di Vostra Eccellenza; ... mi è stato un purgatorio a combattere con tanti artisti ${ }^{28}$.

24 Das Libro mastro I. B. 29, fol. 167, Rubrik Mobili di casa, verbucht unter dem 13. März 1680 eine Zahlung von scudi 39:82 an den Intagliatore Francesco Bergamo per diversi lavori fatti in restaurare il piede del nostro studiolo gioiellato sowie am 10. Juli 1680 scudi 50 an Giacomo [H]Erman a conto de lavori che sta facendo per il piede dello studiolo gioiellato. Aus zwei am 1. März 1680 von Philipp Schor gegengezeichneten Quittungen (in I. A. 62) ist zu erfahren, dass Francesco Bergamo die genannten restauri von Lorenzo Ruez und Ambrogio Fochi ausführen ließ: Io sotto scritto ho lavoratto et restauratto tre mori ... qualli vano sotto ad un tavolino di Ebano per un Piede del Studiollo ... et ho ricevuto a conto di dette Giornate dal Sig. ${ }^{r e}$ Francesco Bergamo Intagliatore di detta Casa scudi $n .{ }^{\circ}$ sei et baiochi $n .{ }^{\circ} 30$ [unterschrieben Lorenzo Ruez]. Io sotto scritto ho aiutatto a restaurare le sudette figure ... [unterschrieben Ambroggio Fochi]. Zu Ruez bzw. Rues siehe unten, Anm. 140.

${ }^{25} \mathrm{Vgl}$. die Beschreibung von Nicodemus Tessin (1687/88): Sonsten wahr auch in einem anderen zimber ein sehr reiches schapp zu sehen mit ein hauffen steinen versetzt, welches $20000 \mathrm{sc}$ : soll gekostet haben; unter es wahren 3 mohren auf den knien zum soustien artig grouppiret, umb ihre köpffe wie auch umb den leibern, armen undt beinen wahren artige ornamenten im feuer verguldet, undt mit gesteinen versetzt, vorn hinter dem ornament auf dhem kopff wahren 5 kleine federn, undt dergleichen wahren dubbelt unter einander rundt umb den leib herumb, so auch alle im feuer vergult wahren. (Nicodemus Tessin the Younger. Sources Works Collections. Travel Notes 1673-77 and 1687-88, hrsg. von M. LaIne-B. Magnusson. Stockholm 2002, 311). Siehe auch: Nicodemus Tessin the Younger. Sources Works Collections. Traictè dela decoration interieure 1717, hrsg. von P. WADDY. Stockholm 2002, 260f. Auf die Beschreibung im Inventar von 1714 (auszugsweise zitiert in Anm. 16) folgt eine Aufzählung der Edelsteine, mit denen die schiavj che reggono detto studiolo bestückt waren: SAFARIK-PUगA (wie in Anm. 2), 281-283.

${ }^{26}$ Libro mastro I. B. 29, fol. 167, Rubrik Mobili di casa: Ab dem 10. Juli 1680 Zahlung von insgesamt 180 scudi an den Orefice Camillo del Ponte a conto de lavori che sta facendo in guarnire il piede del studiolo gioiellato. Siehe dazu auch zwei undatierte Rechnungen von Camillo Delponti Argentiere (in I. A. 62), beide am 5. Dezember 1680 gegengezeichnet von Filippo Schor: per aver fatto una garnitione di metallo dorato e argento con pietre a un piede di studiolo ... bzw. Conto de una gamba fatta al piede dello studiolo .... .

${ }_{27}$ Libro mastro I. B. 29, fol. 202, Rubrik Mobili di Casa.

28 Dokument 16. 
Parallel dazu kümmerte sich Carlo Fontana um den Fortgang der Arbeiten am studiolo d'avorio. Aus mehreren Briefen wird deutlich, dass man die Gebrüder Stainhart verdächtigte, Zeit zu schinden, um ihre Bezahlung in die Höhe zu treiben ${ }^{29}$. Da sie ein festes Monatsgehalt bezogen $^{30}$, sollte Fontana dafür sorgen, dass sie die ihnen übertragenen Aufgaben schnellstmöglich erfüllten ${ }^{31}$. Zwecks Kostendämpfung beabsichtigte er im Februar 1679, il finimento bei anderen Bildschnitzern in Auftrag zu geben ${ }^{32}$ und li troffey (wohl die horizontalen Ornamentstreifen) in Metall gießen zu lassen, wodurch diese Teile schnell, preiswert und gleichmäßig reproduziert werden sollten. Beide Rationalisierungsmaßnahmen blieben schließlich unverwirklicht, nicht zuletzt wegen des solidarischen Widerstandes der römischen Bildschnitzer ${ }^{33}$.

In den Briefen an Lorenzo Onofrio Colonna spielte Geld auch weiterhin eine wichtige Rolle: Beispielsweise brüstete Bologna sich, nur die Hälfte des wahren Wertes für die Reliefs bezahlt zu haben, und ermunterte dann den Principe leicht ironisch, die poveretti mit einem Abschiedsgeschenk zu beglücken ${ }^{34}$. Sowohl Bologna als auch Fontana wollten sich offenbar durch ihre zur Schau getragene Sparsamkeit bei Colonna profilieren, dessen Finanzen damals in einer tiefen Krise steckten. 1679 rechnete der maggiordomo seinem Herrn die strettezza che si ha di denari ausführlich vor und beklagte sich einige Wochen später über il Purgatorio

${ }^{29}$ Dokument 5 und 6; die Kostenfrage ist auch wichtig in den Dokumenten 7 und 10.

${ }^{30}$ Dass die Stainharts eine Zeit lang in festem Sold standen, geht aus der Nachricht hervor, Bologna habe sie von der Gehaltsliste gestrichen (Dokument 10: haverli levati di rollo). Die diesbezüglichen Nachweise befinden sich im Archivio Segreto Vaticano, Fondo Colonna, busta 34 (vgl. Anm. 12).

${ }^{31}$ Dokument 2.

32 Der Begriff finimento kann im gegebenen Kontext zweierlei bedeuten: l'ultima mano che si dà a un prodotto dell'ingegno o dell'arte per rifinirlo e renderlo perfetto oder l'estremità superiore, di natura prevalentemente ornamentale, con cui terminano edifizi, monumenti, oggetti artistici, ecc. (S. Battaglia, Grande dizionario della lingua italiana V. Torino 1968, 1040.) Da im September 1678 von noch nicht begonnenen ornamenti piramidali die Rede ist (Dokument 2), könnte finimento hier im Sinne einer ornamentalen Schrankbekrönung gemeint sein; andererseits spricht Fontana im weiteren Verlauf des Briefes (Dokument 5) von der stilistischen Einheit der Reliefs, was darauf hindeuten könnte, dass zunächst die Fertigstellung aller (auch der figürlichen) Schnitzereien durch andere Künstler erwogen wurde.

${ }^{33}$ Dokument 5.

${ }^{34}$ Dokument 14 
che ho delli Creditori, che mi lacerano ${ }^{35}$. Die Geldknappheit des Principe war sogar so bekannt, dass die römischen Avvisi ab und zu über sie spöttelten $^{36}$.

Im Sinne der Devise „time is money“ musste es Besorgnis erwecken, dass das große Mittelrelief des studiolo d'avorio nicht recht vorankam. Während es am 15. September 1678 hieß, das pezzo maggiore e più riguardevole, che va nel mezzo solle in der folgenden Woche begonnen und innerhalb von drei Monaten fertiggestellt werden ${ }^{37}$, befand sich dieses am 4. März 1679 erst seit vier Monaten in Arbeit und wies molti difetti notabili auf, wie Bologna und Fontana übereinstimmend erklärten; die tode$s c h i$ wurden daher zu Korrekturen auf eigene Kosten verpflichtet ${ }^{38}$. Die Abreise des Besseren der beiden Bildschnitzer nach Neapel senza dire a Dio ist vielleicht als Protest gegen diese Maßnahme zu verstehen ${ }^{39}$. Nachdem Fontana, Teodoli und Bologna in einer Krisensitzung schon über einen Ersatzmann nachgedacht hatten, kehrte Stainhart Ende Mai 1679 zurück $^{40}$. Regelmäßige Zahlungen verbürgen dann kontinuierliche Aktivität $t^{41}$.

In einem Brief vom 1. Oktober 1679 teilte Bologna seinem Herrn mit, der Marchese Teodoli dränge ihn, ein neues Zentralrelief in Auftrag zu geben - eine Maßregel für Fontana, den Teodoli beschuldigte, einen ungeeigneten Entwurf für das Mittelbild zur Ausführung bestimmt zu haben: Die Figuren seien nämlich viel zu groß im Verhältnis zu denjenigen der anderen Reliefs ${ }^{42}$. Die Zahlungen für das Guidicio Universale, das heute den Mittelpunkt der Schrankdekoration bildet, begannen (einer Aufstellung Franz Stainharts zufolge) am 15. September

${ }^{35}$ Briefe von Maurizio Bologna an Lorenzo Onofrio Colonna, 5. Februar 1679 und 28. April 1679 (Carteggio L. O. Colonna 1679, camicia 238).

${ }^{36}$ Avvisi zitiert bei Tamburini (wie in Anm. 7), 13 (Anm. 10), 126 (Nr. 1), 146 (Nr. 2).

37 Dokument 2.

38 Dokument 6.

39 Dokument 7.

40 Dokument 8 und 9 .

${ }^{41}$ Libro mastro I. B. 29, fol. 117, Rubrik Mobili di Casa, Zahlungen ab 6. Juni 1679. Siehe dazu auch die Ausgabenlisten in I. A. 66: Zahlungen an die Gebrüder Stainhart für die Arbeiten am studiolo (Quittungen beiliegend) sowie diesbezügliche Materialkäufe. Weitere Quittungen der Stainharts vom 29. Juli, 29. August, 16. und 20. September 1679 betreffs Arbeiten an bassi rilievi finden sich in I. A. 60; in einer Quittung vom Oktober 1679 heißt es konkret per lavori che facciamo nel pezzo grande, dove si rappresenta il giudizio universale.

${ }^{42}$ Dokument 10. 
$1679^{43}$, somit bereits zwei Wochen vor Benachrichtigung des Principe Colonna. Bologna ließ seinen erwähnten Brief zwar so klingen, als könne Lorenzo Onofrio noch Einspruch erheben, doch in Wirklichkeit war der Austausch des Zentralreliefs bereits beschlossene Sache - ein aufschlussreiches Detail im Hinblick auf die künstlerische Entscheidungsfreiheit des maggiordomo.

Auch im Umgang mit der Justiz nahm sich Maurizio Bologna gewisse Freiheiten, wie aus einem Brief vom November 1679 hervorgeht. Einer der beiden deutschen Bildschnitzer hatte, so berichtete Bologna dem Principe, bei einem Streit auf der Piazza di Spagna einen Landsmann tödlich verwundet - worauf Maurizio dem Übeltäter zunächst im Palazzo Colonna Unterschlupf gewährte und ihn dann außerhalb des Kirchenstaates in Neapel in Sicherheit bringen lie $\beta^{44}$. Dies also war der wahre Kern von Klautes eingangs berichteter Schauergeschichte!

Am 3. Juni 1680 erhielten Francesco e Domenico Stainart die Abschlusszahlung für das Giudicio Universale, das mit insgesamt 200 scudi veranschlagt wurde ${ }^{45}$. Carlo Fontana pries das Werk, das wie ein echter Michelangelo aussehe, in einem Brief vom Juli des Jahres ${ }^{46}$. Interessanterweise bezeichnete Franz Stainhart sich in einer Notiz vom April 1680 als alleinigen Autor des Stückes ${ }^{47}$ - was Feuchtmayrs stilkritische Zuschreibung an Dominikus in Frage stellt ${ }^{48}$. Vielmehr steht zu vermuten, dass Dominikus derjenige war, der sich nach wie vor in Neapel verstecken musste ${ }^{49}$. Da sich die Gebrüder Stainhart bereits 1678 um eine Empfehlung nach Neapel bemüht hatten ${ }^{50}$ und einer der beiden („,der Bessere“, wie Bologna schreibt) im Frühjahr 1679 etwa einen Monat dort verbrachte ${ }^{51}$, dürften sie in jener Stadt eine gewisse Klientel gehabt haben, für die Dominikus

${ }^{43}$ Rechnung von Francesco Stainart, April 1680 (in I. A. 62): $1 l$ pezzo grande di basso rilievo in avorio che rappresenta il Giudicio Universale fatto da Fran. Stainart Scultore Tedesco stimato dal S. Cav. Bernino, et altri importa scudi 200:00. Es folgt eine Auflistung der Zahlungen, die Stainhart vom 15. September 1679 bis März 1680 erhielt, mit der Schlussfolgerung, dass noch scudi 97:10 fehlten; dieser Betrag wurde dann am 3. Juni 1680 ausgezahlt (siehe Anm. 45).

4 Dokument 11.

${ }^{45}$ Libro mastro I. B. 29, fol. 167, Rubrik Mobili di casa.

46 Dokument 15.

47 Vgl. Anm. 43.

48 Feuchtmayr (wie in Anm. 11), 450.

$49 \mathrm{Vgl}$. auch Gozzano (wie in Anm. 1*), 244: Am 13. April und 10. Mai 1680 erfolgten Zahlungen nur an Franz Stainhart.

${ }^{50}$ Dokument 2.

51 Dokument 7, 8. 
vielleicht auch im Winter 1679/80 arbeitete. Es wäre daher zu überlegen, ob die von González-Palacios mit dem Colonna'schen Prunkmöbel verglichenen Elfenbeinreliefs eines süditalienischen Kunstschranks während der besagten Neapelaufenthalte entstanden sein könnten ${ }^{52}$.

Der Brief, der dem Principe Colonna am 6. Juli 1680 die Vollendung aller Reliefs seines studiolo anzeigte, nennt als Absender Domenico (e) Francesco Stainardi tedeschi, doch folgt daraus nicht zwangsläufig, dass beide damals in Rom weilten, da der Text mitsamt der zwei ,Unterschriften' nur von einer einzigen Hand (möglicherweise von einem professionellen italienischen Schreiber) stammt. Das Schriftstück spielt in der Wortwahl (purgatissimo giuditio, ultimo sforzo) subtil auf das Thema des zentralen Gerichtsreliefs an und schmeichelt zugleich dem Fürsten wegen seines Kunstverständnisses: L'ardire, che pigliamo di comparire avanti a Vostra Eccellenza con queste poche righe, non da altro proviene, che da un impulso d'una divotissima osservanza, la quale ci obbliga con ossequij di riverenza a darle parte come già habbiamo havuto l'honore d'haver finito tutta l'opera dello studiolo; E perchè l'Eccellenza Sua come Signore, che con l'occhio del suo rettissimo, e purgatissimo giuditio avanti la partenza in vedere alcuni pezzi già fatti ne diede segno di gradimento, cosi speriamo, che nel ritorno, che pregando Iddio che esaudisca li nostri voti ad esser presto, Vostra Eccellenza incontrerà le medesime sodisfattioni, mentre habbiamo fatto l'ultimo sforzo in operare con quella attentione, che è propria d'un servitore che ambisce di servire un Signore di tanto merito ${ }^{53}$.

In Wirklichkeit war Lorenzo Onofrios Anteilnahme an dem Projekt geringer, als es aufgrund dieser Zeilen erscheinen mag. Der Brief, mit dem Maurizio Bologna ihn über die Fertigstellung des studiolo d'avorio unterrichtete, verrät erneut eine recht große Entscheidungsfreiheit der römischen Sachverständigen: in quanto all'historie da farsi ne bassi rilievi mi son governato con i pareri del Signor Marchese Teodoli, Cavalier Bernino, Filippo Schor, et altri Professori, mentre il Fontana dal principio errò in alcuni pezzi e particolarmente nel Grande. Il pezzo grande è il giuditio Universale di Michel Angelo, la strage degl'Innocenti del Rubens, la Resurretione del Signore parimente di Michel Angelo, la Crocifissione del Signore di Lanfranco, et altri pezzi che sono al numero di sei che restorno da farsi quando Vostra Eccellenza parti mi dicano tutti che siano ben fatti ... ${ }^{54}$.

Am 12. Juli 1680 informierte Carlo Fontana den Principe, dass die Montage des Schrankes begonnen habe: Si è messo insieme sopra la tavo-

${ }^{52}$ González-Palacios, Il Tempio (wie in Anm. 4), I, $219 \mathrm{f}$. und II, 168.

53 Dokument 13.

${ }^{54}$ Dokument 14. 
la dove fù disegnato il studiolo tutti li pezzi d'avorio ${ }^{55}$. Bei der besagten tavola handelte es sich höchstwahrscheinlich um eben jene tavola longa palmi ondeci incirca, die Giacomo Herman 1677 hergestellt hatte per far un disegno sopra del cavaliere Fontana ${ }^{56}$. Die Maße der tavola und des ausgeführten Schrankes stimmen überein ${ }^{57}$, d. h. auf der Tafel befand sich offenbar eine Zeichnung des Möbels in Originalgröße, auf der 1680 die fertiggestellten Elfenbeinteile ausgelegt bzw. appliziert wurden, bevor Herman das tragende Gerüst des Schrankes konstruierte. Im Dezember 1680 begann Herman die Arbeit an dem Corpus des Studiolo sopra un disegno straordinario fatto dal Cavaliere Fontana ${ }^{58}$.

1681 schätzte Bologna, dass die Fertigstellung des Schrankes bis mindestens 1682 dauern würde ${ }^{59}$; schließlich war aber erst Ende 1684 das Wichtigste geschafft. Andrea Linili schnitzte acht Kapitelle und Basen sowie einige cornicette aus Elfenbein ${ }^{60}$, der Ebanista Herman stellte stolze 950 scudi für lavori fatti per lo studiolo di Ebano e bassi rilievi d'avorio in Rechnung ${ }^{61}$, und der Schrank wurde endlich in den Palazzo Colonna transportiert ${ }^{62}$. Bei seinem Rombesuch 1687/88 bewunderte Nicodemus Tessin bereits ein grosses schapp ... voller bassarilieven von elffenbein, sehr ins kleine undt sauber aussgemacht, worunter dess M. A. Buonaroti Jüngstes Gericht wahr representiret, ${ }^{63}$ doch die Fortsetzung der Arbeiten schleppte

${ }^{55}$ Dokument 15.

${ }^{56}$ Dokument 1 unter dem Datum 26. April 1677

${ }^{57}$ Der Schrank ist laut Inventar von 1714 palmi dieci, et onze cinque breit: SAFARIK-PUJA (wie in Anm. 2), 283f., Nr. 564.

${ }^{58}$ Conto nuovo ... di un studiolo fatto nella bottega di Giacomo Herman per ordine proprio di sua Eccellenza di Ebano intarsiato di avoglio, dove entravano alcuni bassi rilievi pur di avoglio fatti fatti [sic] fare da Sua Eccellenza ... fatto sopra un disegno straordinario fatto dal Cavaliere Fontana cominciato alli 16 decembre 1680 (in I. A. $89)$.

${ }^{59}$ Dokument 17.

${ }^{60}$ I. EK. 23, fol. 64: Zwischen dem 18. August 1683 und dem 31. Dezember 1684 lieferte der Mercante di Avorio Pietro Emiliani für scudi 58:95 Avorio dato per li Capitelli Base et alcune Cornicette del Studiolo di bassi Rilievi; siehe die diesbezügliche Rechnung von Emiliani in I. A. 70. Der Intagliatore d'Avorio Andrea Linili erhielt 1684 per prezzo di $n .{ }^{\circ} 8$ Capitelli dico per intagliatura di detti Capitelli d'Avorio scudi 44:00 (I. EK. 23, fol. 70). Siehe dazu auch Libro mastro I. B. 29, fol. 382, sowie I. B. 30, fol. 150, jeweils Rubrik Mobili di Casa.

${ }^{61}$ I. EK. 23, fol. 21 (unter dem Datum 31. Dezember 1684).

${ }^{62}$ Ausgabenliste des mastro di casa Giulio Grappolini für Dezember 1684 (in I. A. 68): giulij sei pagati a sei facchini che fecero più viaggi in portare il studiolo d'ebano con l'intagli d'avorio al palazzo.

${ }^{63}$ Latne-Magnusson (wie in Anm. 25), 312. Siehe auch Waddy (wie in Anm. 25), 260. 
sich träge dahin. Ein weiterer Ebanista bekam bis 1689 seine Mühen betreffs des studiolo d'avorio vergütet ${ }^{64}, 1690$ wurde ein Wachsmodell des Schrankes farbig gefasst ${ }^{65}$, 1692 standen Zahlungen aus für il piede dello studiolo nobile non potuto terminarsi per mancanza dell'Avorio ${ }^{66} .1693$ war der Schrank immer noch nicht fertig ${ }^{67} .1699$ raffte man sich zu letzten Werkeleien am besagten piede auf ${ }^{68}$, wohl schon im Zusammenhang mit dem Transport des Möbels in die Galerie, wo es Anfang 1700 sopra la tavola dei mori installiert wurde ${ }^{69}$. Dort sah bereits im Februar 1700 Johann Balthasar Klaute das Prunkstück.

Wenig später fanden in der Galerie auch die neuen Konsoltische Aufstellung, die das an den beiden Prunkschränken erprobte Motiv der tragenden Orientalen variieren. Am Schnitzwerk jener Tische wurde ab dem 12. Juni 1700 gearbeitet $^{70}$. Die abschließende Rechnung über die Alabas-

${ }^{64}$ I. EK. 23, fol. 67: Domenico Ibijef [andere Namensformen: Jef bzw. Jeffe] bekam per servitio del Studiolo d'avorio dal 1684 a tutto 15. Ap. 1689 scudi 100:00.

65 Eine Rechnung des indoratore Francesco Corallo für den Zeitraum 1. Januar 1688-31. Dezember 1690 (in I. A. 86) berechnet unter dem Datum 22. Dezember 1690 scudi 0:60 per haver colorito il Modello del Studiolo di Cera, che doveva farsi d'ebano et avorio.

${ }^{66}$ Rechnung des intagliatore Isidoro Beati (in I. A. 86) unter dem Datum 15. Februar 1692.

${ }^{67}$ Ein 1693 erschienener Romführer erwähnt im Palazzo Colonna un Studiolo bellissimo di ebbano ornato di bassi rilievi d'avorio, quando sarà finito costarà dicidotto mila scudi. (P. Rossini, Il Mercurio Errante delle Antichità di Roma. Roma 1693, Libro primo, 46).

68 Rechnung des falegname Giovanni Canavese unter dem Datum 2. Mai 1699 (I. A. 108, Nr. 179).

69 Rechnung des ferraro Giovanni Conti (I. A. 108, Nr. 121): zwischen dem 5. und 13. Januar 1700 Lieferung von tre ferri ... per reggere lo studiolo sopra la tavola dei mori in galleria. Eine Misura e stima über Arbeiten des Capo mastro muratore Antonio Giobbe (I. A. 112, Nr. 200) vermerkt zu einem nicht näher bestimmten Zeitpunkt vor dem 20. August 1700 mit Bezug auf den westlichen Anraum der Galerie portatura e mettitura in opera delli due studioli messi in detto cammerone cioè quello d'avolio e quello d'ebbano, et anche quello delle gioie messo nella cammera dove dorme Sua Eccellenza portati dall'appartamento verso la Pilotta in detti luoghi. Demnach gelangte das studiolo delle gioie (Abb. 4) zunächst nicht in die Galerie - was auch mit den Angaben im Inventar von 1714 korrespondiert, das eben jenes Möbelstück in dem vor der Galerie gelegenen Zimmer lokalisiert.

${ }^{70}$ Rechnung von Giovanni Battista Antonini mit beiliegenden Quittungen (in I. A. 114): Am 12. Juni 1700 findet sich erstmals eine Quittung über eine Zahlung per pagare le giornate delli omini che lavorono nelli tavolini. Zahlreiche weitere Quittungen per $i$ tavolini della Galleria folgen bis zum 18. September 1701, darunter auch (ab dem 9. Januar 1701) etliche betreffs Vergoldung der Tische. Aus der abschließenden Zusammenfassung geht hervor, dass die tavolini 1127:94 scudi kosteten. 


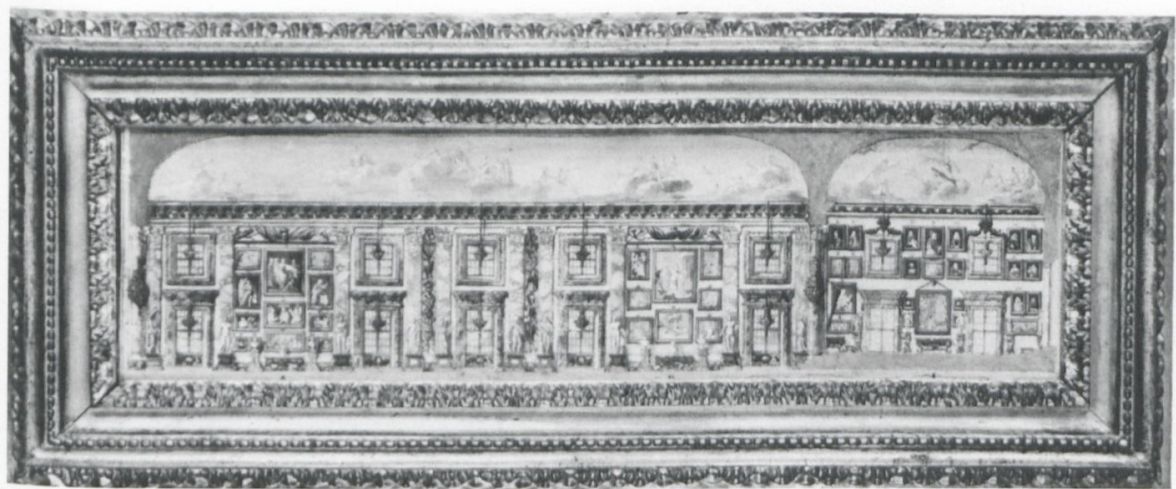

Abb. 5: Aquarellierter Querschnitt durch die Galleria Colonna (Ansicht der Nordseite): Rom, Sammlung Colonna

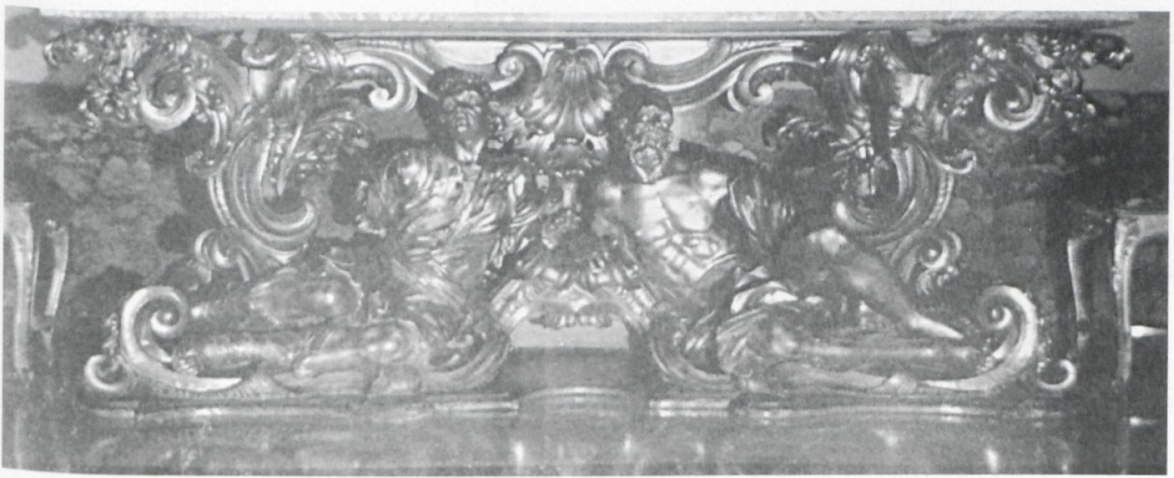

Abb. 6: Rom, Galleria Colonna, Konsoltisch im Mittelsaal

terverkleidung der acht Tischplatten datiert zwar erst von $1703^{71}$, doch informiert bereits ein Dokument von 1701 über die Platzierung der Möbel in der Galerie ${ }^{72}$. 1702 wurden dann noch einmal vier Konsolen umge-

${ }^{71}$ I. A. 120, Nr. 174 (siehe unten, Anm. 74).

${ }^{72}$ Misura e stima über Arbeiten des Capo Mastro Muratore Antonio Giobbe im gesamten Jahr 1701 (I. A. 115, Nr. 222): ... Per haver scaricato da i Carri li tre lastroni di Peperino, che sono serviti per fodere delli Tavolini d'alabastro orientale in Galleria ... e dopo segati detti lastroni, e fattone otto pezzi portati nella stanza assegnata per lo scarpellino al Casino alla Pilotta (scudi 6:00) / .../Per aver preso con 12 uomini per volta li tavolini d'alabastro dalla bottega dello scarpellino a Montecitorio, imbragati con corde, e portati in più e diversi tempi con scomodo grande e diligenza per lo scalone del Casino alla Pilotta, e di li in galleria, e portati nel palazzo del detto Cardinale Camerlengo passati in giardino, e portati per il ponte in galleria, e postivi $i$ cavalletti (scudi 24:00) / Per aver levato dalli cavaletti li otto tavolinigrandi di alabastro in galleria, e posti in più tempi sopra li piedi d'intaglio ... scudi 6:00. 


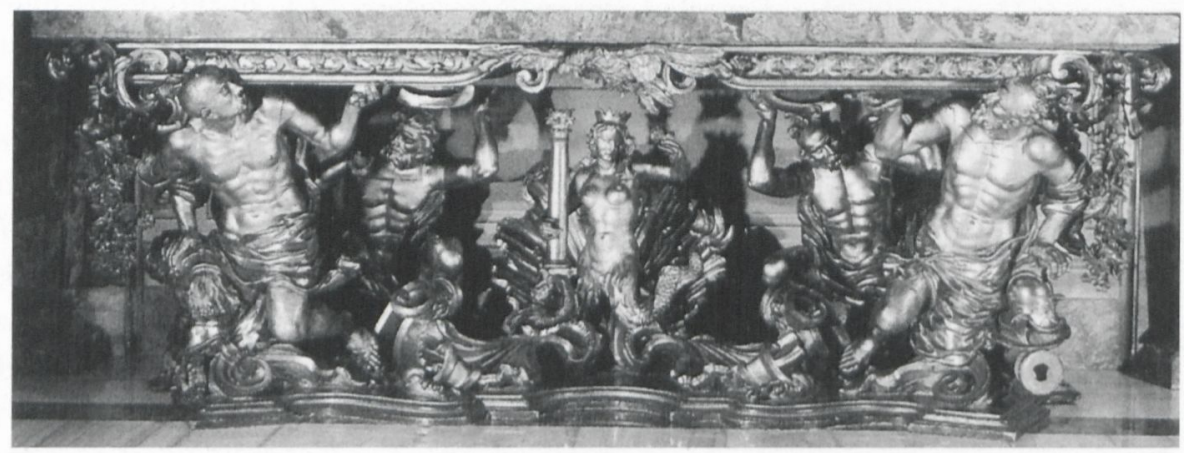

Abb. 7: Rom, Galleria Colonna, Konsoltisch im östlichen Anraum

stellt ${ }^{73}$ - vermutlich jene, die in den zuletzt vollendeten östlichen Anraum gelangten. Wie aus der Steinmetzrechnung hervorgeht, existierte bereits 1703 die Anordnung, die ein Aquarell der Sammlung Colonna (Abb. 5) dokumentiert: Den Mittelsaal der Galerie schmückten damals wie heute vier Tische mit einem Unterbau aus je zwei liegenden Orientalen (Abb. 6); im östlichen Anraum standen zwei ebenso große, aber aufwändiger ornamentierte Konsolen (Abb. 7) sowie zwei etwas kleinere, neben dem Durchgang platzierte Tische, jeweils von Spiegeln überfangen ${ }^{74}$.

Das Inventar von 1714 erwähnt im westlichen Anraum der Galerie ferner die ähnlich gestalteten, aber deutlich kleineren Konsoltische (Abb. 8), die ebenfalls noch heute dort zu sehen sind (Abb. 1) $)^{75}$. Der erste dieser Tische befand sich bereits 1686 in Arbeit $^{76}$ und wurde 1688 teils

${ }^{73}$ Misura e stima über Arbeiten des Capo Mastro Muratore Antonio Giobbe im gesamten Jahr 1702 (I. A. 117, Nr. 117) unter der Überschrift Segue nella galleria.

74 Die Misura e stima über Steinmetzarbeiten des Nicola Corona für das gesamte Jahr 1703 (I. A. 120, Nr. 174) berechnet unter der Überschrift In galleria die Verkleidung (commesso) folgender acht Tischplatten: per il commesso di alabastro orientale di una delle tavole grandi tra li scabelloni di pietre mischie long. palmi 12 larg. palmi 5 ... (scudi 35:66) / per il commesso di numero 3 altre tavole simili / per il commesso di alabastro orientale colorito di una delle tavole nel stanzione in testa a detta galleria verso la Pilotta nel resalto accanto la colonna di giallo ... long. palmi 9 2/3 larg. palmi 5 (scudi 25:57 ) / per il commesso di un'altra tavola simile / per il commesso di alabastro fiorito di una delle tavole sotto li specchi grandi in detto stanzione nelli due fianchi long. palmi 12 larg. palmi 5 ... (scudi 31:46) / per il commesso di un'altra tavola incontro la sudetta.

75 Safarik-PuJa (wie in Anm. 2), 283, Nr. 559.

${ }^{76}$ Rechnung des Isidoro Beati Intagliatore al Corso (in I. A. 86) unter dem Datum 29. November 1686: per haver intagliato un sasso con un Alberetto di Lauoro in mezzo per adattarvi due schiavi quali devono servire per piede di tavola con sopra il suo telaro scorniciato attorno (scudi 18:00). Eine zweite Rechnung desselben (dito 


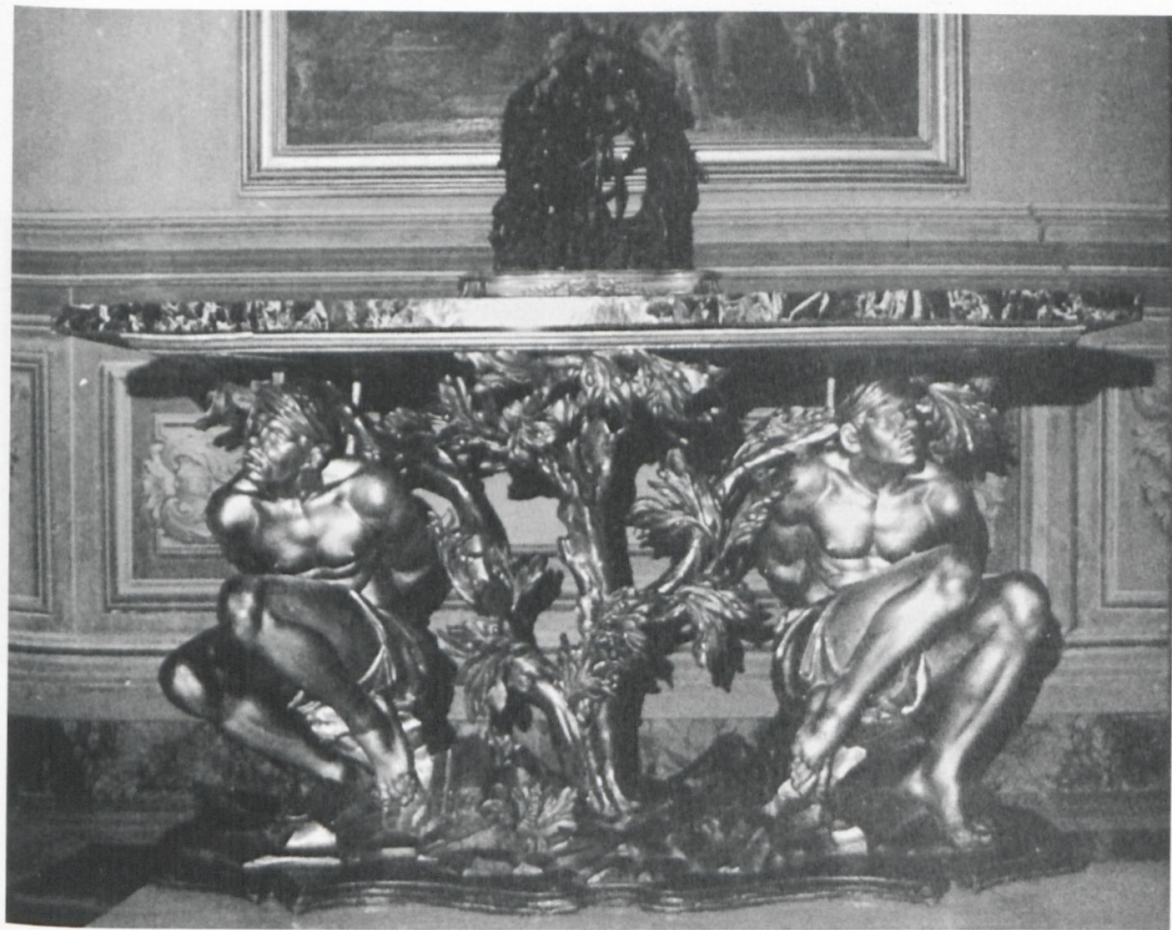

Abb. 8: Rom, Galleria Colonna, Konsoltisch im westlichen Anraum

vergoldet, teils farbig gefasst ${ }^{77}$; das Pendant datiert von $1692^{78}$. Vermutlich gelangten die beiden Stücke vor 1703 an ihren gegenwärtigen Standort ${ }^{79}$.

in I. A. 86) erwähnt unter dem Datum 4. April 1688 bzw. 20. November 1688 weitere Arbeiten an eben jenem Tisch.

77 Rechnung des indoratore Francesco Corallo für den Zeitraum 1. Januar 1688 31. Dezember 1690 (in I. A. 86) unter dem Datum 17. Februar [1688]: per haver indorato un piede di tavolino fatto à scoglio con un albero d'olivo con due Mori depinti del suo naturale con pan ( $n$ ) o intorno, e fascia in testa dorato brunito (scudi 20:00).

${ }^{78}$ Rechnung des intagliatore Isidoro Beati (in I. A. 86) unter dem Datum 10. Juni 1692: per havere fatto un Tavolino per due Mori che stavano in casa detto Tavolino fatto in conformità di quello che era in casa dorato (scudi 16:00). Rechnung des indoratore Francesco Corallo für Arbeiten ab 4. Februar 1691 (in I. A. 86) unter dem Datum 6. Juli 1692: per havere indorato un piede di tavolino con un'Albero d'oliva con due Mori dipinti a olio et il resto con panni in testa dorato tutto brunito (scudi 25:00). Misura e Stima über Arbeiten der muratori Giovan Pieroni und Antonio Giobbe im Zeitraum 1. Februar 1692-31. April 1693 (in I. A. 86) unter dem Datum 5. Juli 1692: per haver preso un piede di tavolino con due mori presi alla bottega di Corallo, e portati nell'Appartamento dell Signore, e preso il tavolino nella Capella di S. Carlo, e posto sopra detto piede (scudi 0:40).

79 Eine Rechnung des indoratore Francesco Corallo für Arbeiten bis Ende 1703 (I. A. 120, Nr. 166) lokalisiert die Tische accanto alla galleria, was durchaus den 
Die Möblierung der Galleria Colonna zeichnet sich folglich seit Beginn des 18. Jahrhunderts durch große Einheitlichkeit aus. Das Motiv der unterworfenen Orientalen kehrt in allen drei Teilbereichen der Galerie wieder: Während im westlichen Anraum Mohren auf engstem Raum unter den vergleichsweise kleinen Tischplatten kauern (Abb. 8), breiten sie sich im großen Mittelsaal unter entsprechend großen Tischen würdig wie antike Flußgötter aus (Abb. 6) und rahmen schließlich im östlichen Anraum in einer besonders reichen Komposition die Colonna-Embleme Sirene und Säule (Abb. 7) ${ }^{80}$. Die steigernde Tendenz, die in der Architektur angelegt ist, indem sich der östliche Anraum um einige Stufen über

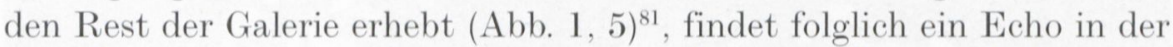
Möblierung, welche zudem thematisch auf das Gesamtprogramm abgestimmt ist: Die orientalischen ,Gefangenen' alludieren nämlich auf das Thema der Deckenfresken (Marcantonio Colonnas Türkensieg bei Lepanto $)^{82}$. Im östlichen Anraum, in dem der Höhepunkt des Programms, Marcantonios Apotheose, erreicht ist, trumpfen selbst die Möbel mit einer allegorischen Huldigung auf (Abb. 7), wobei als besonderer Clou über Sirene und Säule noch die Taube schwebt, Wappenzeichen der Hausherrin Olimpia Pamphilj und triumphales Friedenssymbol in einem ${ }^{83}$.

Unter den Kunstmöbeln der Galleria Colonna ragt das studiolo d'avorio (Abb. 2) zweifellos als das virtuoseste und originellste Stück hervor. Auf figuralen ,Trägern' ruhend, präsentiert sich der Ebenholzschrank als eine ,Miniatur-Architektur', deren Fassade mit Kleinbronzen und 28 elfenbeinernen Miniatur-Reproduktionen berühmter Kunstwerke des 16. und

westlichen Anraum meinen könnte (per haver ritinti numero 4 moretti che stanno attorno due tavolini che stanno accanto alla galleria).

${ }^{80}$ Zur Omnipräsenz von Sirene und Säule im Palazzo Colonna siehe SAFARIK (wie in Anm. 4), 16-46.

${ }^{81}$ Zur besonderen Bedeutung des als, Thronsaal' gedachten östlichen Anraumes vgl. Strunck, Lorenzo Onofrio Colonna (wie in Anm. 3).

${ }^{82}$ Zum Programm ausführlich STRunck (wie in Anm. 21); eine Kurzfassung bietet C. StRunck, Die Konkurrenz der Paläste: Alter Adel versus Nepoten im Rom des Seicento, in: Die Kreise der Nepoten. Neue Forschungen zu alten und neuen Eliten Roms in der frühen Neuzeit, hrsg. von D. Buchel-V. Reinhardt. Bern u.a. 2001, 203-233.

${ }^{83} \mathrm{Zu}$ Olimpia Pamphilj vgl. SAFARIK (wie in Anm. 4), 38; zur barocken Ausdeutung des Pamphilj-Wappens R. Premesberger, Pontifex Romanus per Aeneam Praesignatus. Die Galleria Pamphilj und ihre Fresken. Römisches Jahrbuch für Kunstgeschichte 16 (1976), 221-287. 


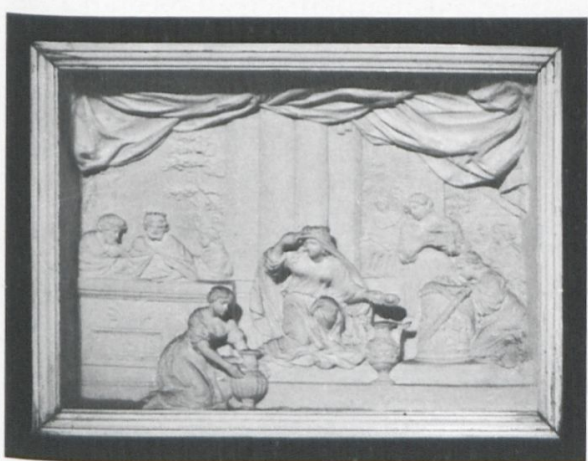

Abb. 9 a: Detail: ,Antiochus III. und die Priesterin der Diana " (nach Pietro da Cortona)

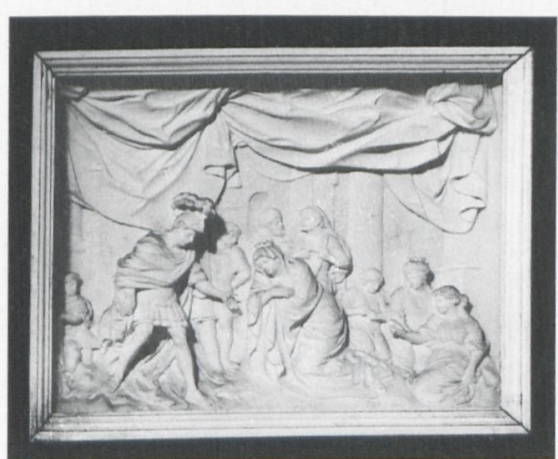

Abb. 9 e: „Alexander und die Frauen des Darius" (nach Pietro da Cortona)

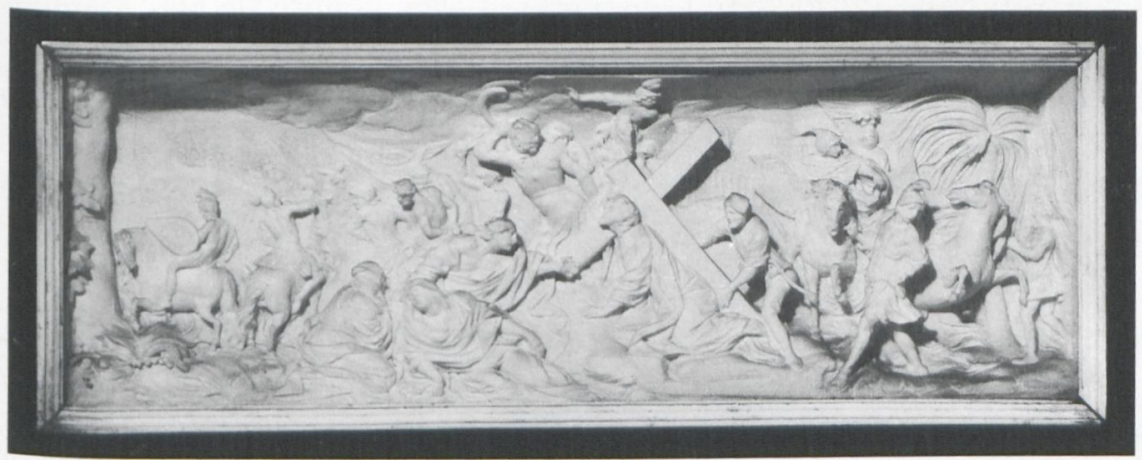

Abb. 9 b: Rom, Galleria Colonna, Kabinettschrank mit Elfenbeinreliefs der Gebrüder Stainhart, ,Kreuztragung“

(nach Giovanni Lanfranco), 
17. Jahrhunderts geschmückt ist. Bevor ich in Abschnitt III auf die Architekturformen und die Stützfiguren zu sprechen komme, möchte ich zunächst die Reliefs eingehender betrachten.

Die Aufgabe der Gebrüder Stainhart bestand darin, Meisterwerke der bildenden Kunst in das Miniaturformat ihrer Elfenbeinschnitzereien umzusetzen. Dabei dienten ihnen größtenteils Stiche als Vorlage, wie sich daran erkennen lässt, dass viele Reliefs im Vergleich zu ihrem Vorbild seitenverkehrt sind. Als Beispiele seien zwei Reliefs nach Fresken Pietro da Cortonas herausgegriffen (Abb. 9a und 9c, 10, 11) ${ }^{84}$. Der Vergleich zwischen den Fresken, den sehr exakten (aber seitenverkehrten) Reproduktionsgraphiken und den Reliefs zeigt, in wie starkem Maße die Gebrüder Stainhart ihre Modelle kreativ umgestalteten. Sie kopierten zwar die Hauptfiguren von Cortonas Fresco „Alexander der Große und die Familie des Darius", versetzten das Geschehen aber in ein völlig anderes Ambiente (Abb. 9c, 10). Die große Draperie, die die Figuren überfängt, um den Formatunterschied zwischen bogenförmig abschließendem Lünettenfresco und rechteckigem Relief auszugleichen, erinnert an Charles Le Bruns Darstellung derselben Szene. Das Zelt, in dem die geschilderte Begegnung stattgefunden haben soll ${ }^{85}$, nimmt bei Le Brun ähnlich prominent die obere Bildhälfte ein $^{86}$. Da eine auf eben jenem Gemälde Le Bruns basierende Tapisserie im Palazzo Colonna existierte, könnte sie als ,Anschauungsmaterial' durchaus den besagten Eingriff in Cortonas Komposition inspiriert haben ${ }^{87}$. Bei Le Brun findet sich jedoch nicht die Säule im Hintergrund. Die Stainharts scheinen sie eingefügt zu haben, um das Relief mit seinem Pendant, „Antiochus III. und die Priesterin der Diana“, zu parallelisieren, wo ebenfalls im Hintergrund eine Architektur zu sehen ist

${ }^{84}$ Wie unten näher erläutert, gehören die hier besprochenen Reliefs zu einem Zyklus von insgesamt sechs ,Kopien' nach Cortonas Dekoration der "Sala di Venere " im Florentiner Palazzo Pitti. Zu den Nachstichen dieser Dekoration siehe M. Turrio Baldassarri, Pierre de Cortone dans les gravures françaises du XVIIe siècle. Gazette des beaux-arts 126 (1995), 27-52; hier 45f., Nr. 58-60; B. GADY, Una gloria senza fortuna: Pietro da Cortona e la Francia (1628-1669), in: Pietro da Cortona 1597-1669, hrsg. von A. Lo Bianco. Milano 1997, 153-163, hier 163, Nr. 58 60; DERs., Gravure d'interprétation et échanges artistiques. Les estampes françaises d'après les peintres italiens contemporains (1655-1724). Studiolo 1 (2002), 64-104, hier 76, 88 (Anm. 89).

${ }^{85}$ M. Campbell, Pietro da Cortona at the Pitti Palace. A Study of the Planetary Rooms and Related Projects. Princeton 1977, 101.

${ }^{86}$ A. T. Birkenholz, Die Alexander-Geschichte von Charles Le Brun. Historische und stilkritische Untersuchungen der Werkentwicklung. Frankfurt a. M. u. a. 2002, Abb. 1 und Abb. 25.

87 SAFARIK (wie in Anm. 4), 264, Abb. 464. 


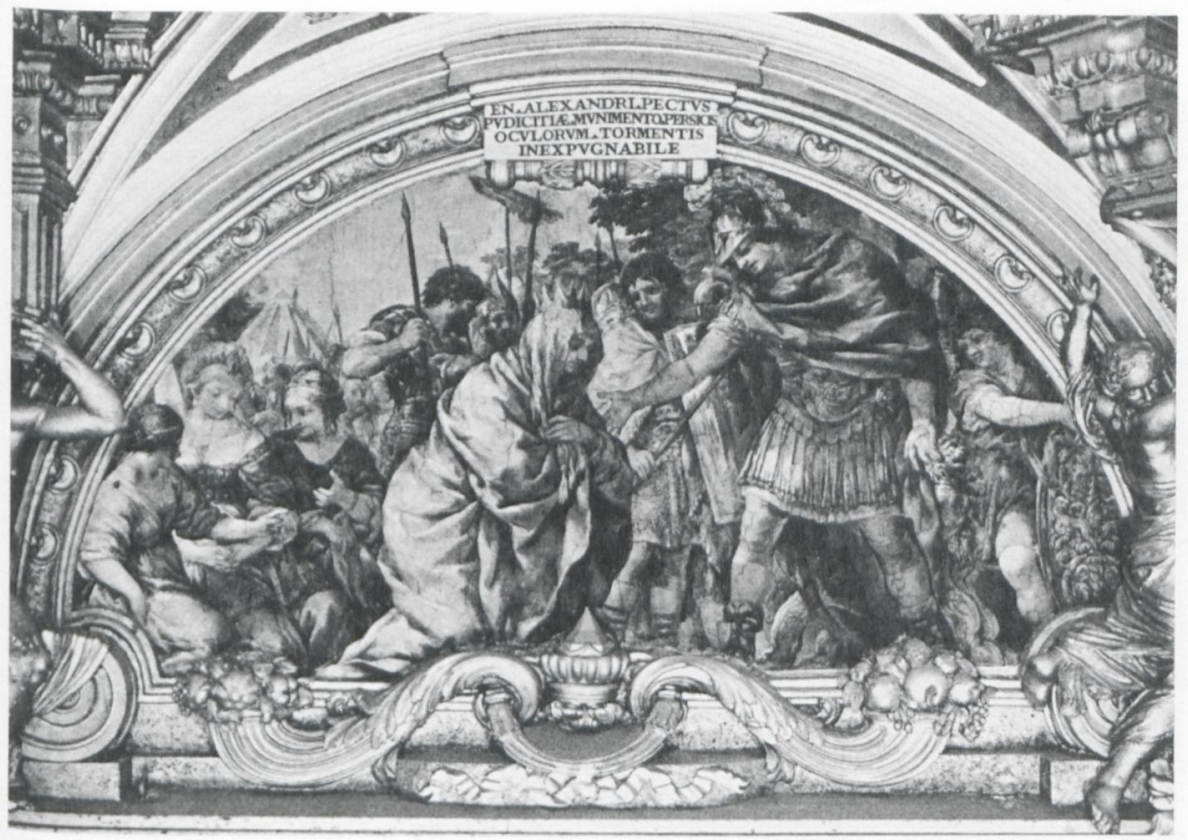

Abb. 10: Florenz, Palazzo Pitti, Sala di Venere: „Alexander und die Frauen des Darius" (Pietro da Cortona)

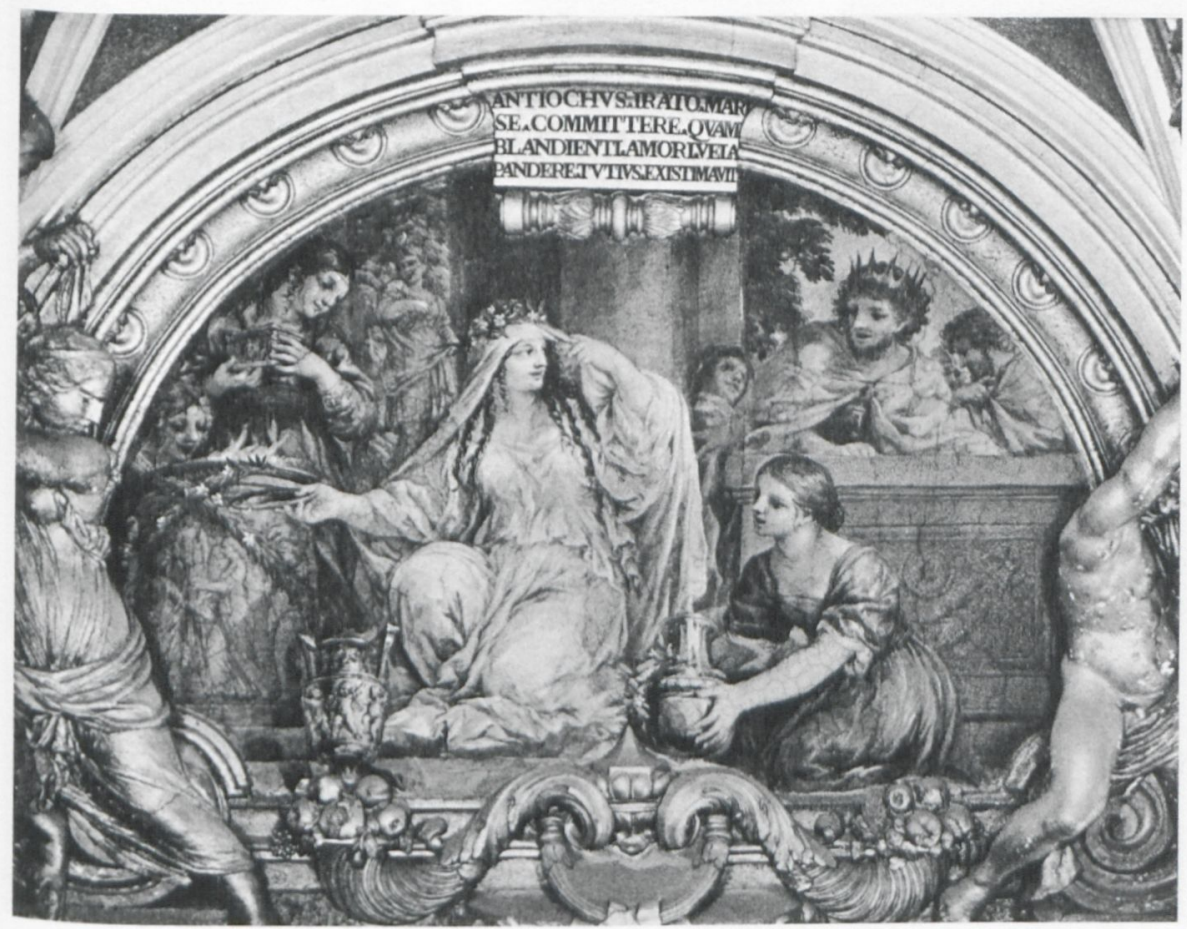

Abb. 11: Florenz, Palazzo Pitti, Sala di Venere: „Antiochus III. und die Priesterin der Diana " (Pietro da Cortona) 
$(\text { Abb. 9a, 11 })^{88}$. Die Draperie, die wiederum in Abweichung von Cortonas Vorbild die Raumbühne nach oben abschließt, verstärkt die formale $\mathrm{Pa}$ rallele. Beide Szenen werden durch eine im Bildmittelpunkt kniende Frau beherrscht und sind spiegelbildlich aufeinander bezogen, da im linken Relief die Hauptbewegungsrichtung nach links, im rechten Relief jedoch nach rechts verläuft (Abb. 9a und 9c). Die Bildschnitzer unterstrichen die kompositionelle Ähnlichkeit, indem sie die hinter dem Altar stehende Gehilfin der Priesterin, die bei Cortona nur am Rande hervorlugt (Abb. 11), frei in den Raum hineinrückten und sie somit zu einem optischen Pendant Alexanders des Großen machten (Abb. 9a und 9c, 10).

Das von den beiden symmetrisch angeordneten Cortona-,Kopien gerahmte mittlere Relief (Abb. 9b) ging mit der Vorlage sogar noch freier um. Bei Giovanni Lanfrancos „Kreuztragung“ handelt es sich um eine hochrechteckige, auf wenige Figuren beschränkte Komposition (Abb. $12)^{89}$. Obwohl das Original in der Cappella Sacchetti in S. Giovanni dei Fiorentini für die Gebrüder Stainhart problemlos zugänglich gewesen wäre, griffen sie nicht auf eine eigene Zeichnung des Objekts, sondern wiederum auf einen Stich zurück, wie ein Zahlungsdokument belegt $\mathrm{t}^{90}$. Die Vorlage wurde aber beträchtlich erweitert: Nur das mittlere Drittel des Reliefs geht auf Lanfrancos Gemälde zurück, während die beidseitig angefügten Reitergruppen dem Werk eine horizontale Ausrichtung verleihen, die die diagonal nach oben (zum Ort der Kreuzigung) strebende Dynamik des Originals zunichte macht.

Die Veränderungen, die die Gebrüder Stainhart an den drei besprochenen Szenen vornahmen, zeigen an, dass in diesen Fällen bereits vorab feststand, wo die Schnitzereien angebracht werden sollten. Lanfrancos Komposition musste offenbar in die Breite gezogen werden, weil sie den Platz unter dem ebenso breiten Mittelrelief einnehmen sollte (vgl. Abb. 2), und die formale Parallelisierung der beiden cortonesken Reliefs deutet

${ }^{88}$ Da die Säule das Wappenzeichen der Familie Colonna ist, könnte sie auch als Anspielung auf den Auftraggeber verstanden werden; doch dürfte die gewünschte formale Parallelisierung mit dem Pendant-Relief der naheliegendere Grund für ihre Präsenz sein.

${ }^{89}$ G.-P. Bernini, Giovanni Lanfranco (1582-1647). Parma ${ }^{2} 1985$, 61; E. Schleier, Note sul percorso artistico di Giovanni Lanfranco, in: Giovanni Lanfranco. Un pittore baroceo tra Parma, Roma e Napoli, hrsg. von E. SchleiER. Milano 2002, 27-52; hier 41 .

90 Die Liste Esito delli denari für Juni 1679 (in I. A. 66) erwähnt unter dem Datum 2. Juni die Zahlung von scudi 0:50 per due carte stampate rappresentanti il Salvatore che porta la croce al calvario, e furono prese per farle fare in basso rilievo d'avorio, per ponerlo allo studiolo che lavorano li Todeschi. 


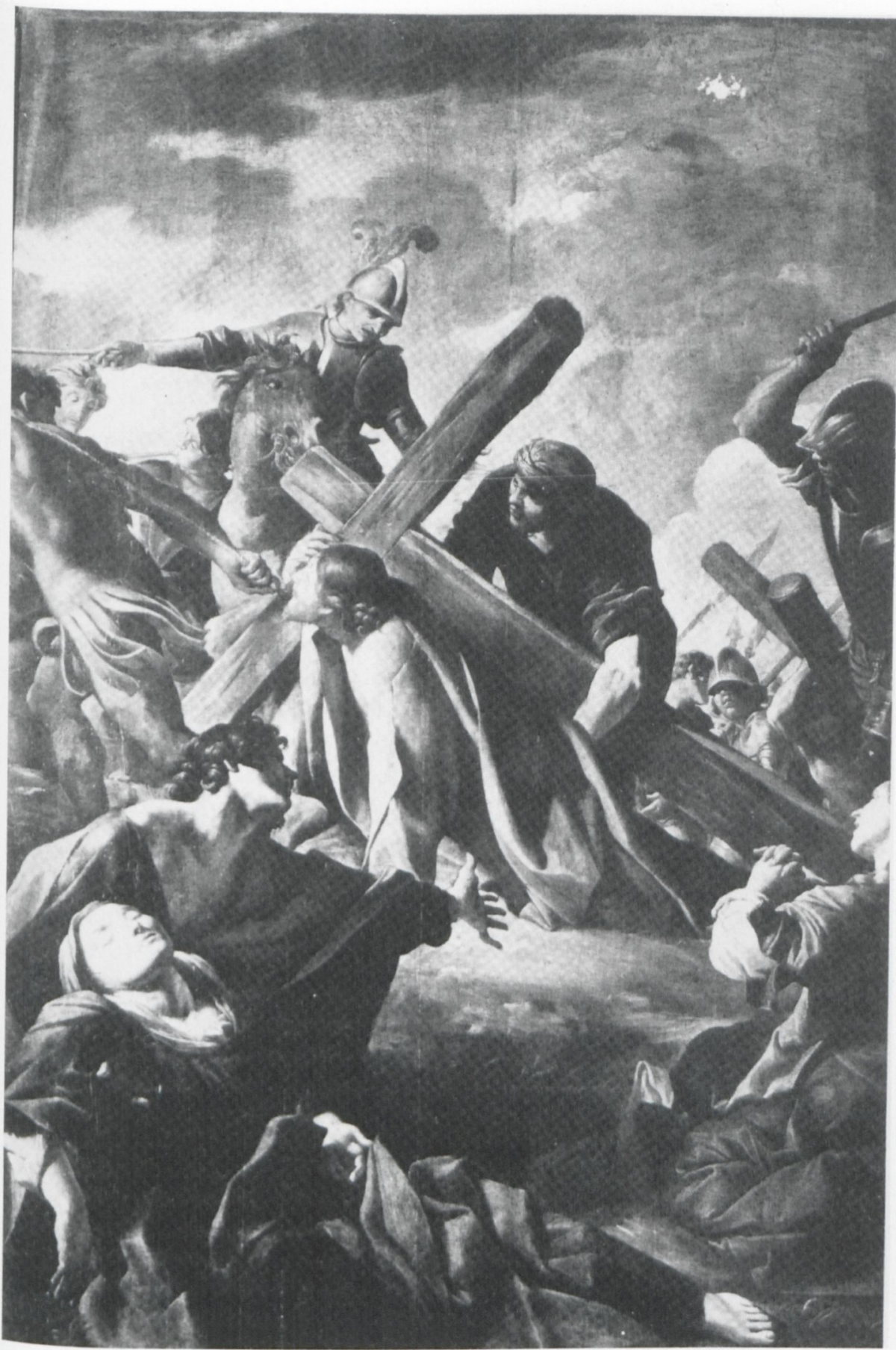

Abb. 12: Rom, S. Giovanni dei Fiorentini, Cappella Sacchetti: „Kreuztragung“ (Giovanni Lanfranco) 
darauf hin, dass sie von Anfang an als Pendants gedacht waren. Diese Beobachtung wirft die Frage nach dem ,Programm' des Schrankes auf, das bisher in der Forschungsliteratur noch nicht analysiert wurde. Inwiefern lässt sich aus Themen und Positionierung der 28 narrativen Reliefs ein Gesamtkonzept ablesen?

Vorab sei zunächst kurz resümiert, was die in Abschnitt I ausgewerteten Dokumente über die Programmgenese verraten. Vor Lorenzo Onofrio Colonnas Abreise nach Spanien (1678) waren zwar bereits etliche Schnitzereien vollendet, doch stand in mindestens zehn Fällen noch nicht fest, welche Werke zu kopieren seien. Der Auftraggeber überließ die Auswahl anderen - seinem maggiordomo Maurizio Bologna, dem Marchese Teodoli und Künstlern wie Gianlorenzo Bernini, Philipp Schor und Carlo Fontana ${ }^{91}$. Fontana, ,künstlerischer Leiter ' der Arbeiten am Kabinettschrank, traf die verantwortungsvolle Entscheidung über die Vorlage für das besonders große und wichtige Mittelrelief. Er wollte offenbar einen markanten visuellen Akzent setzen und wählte eine großfigurige Darstellung. Dies missfiel jedoch Bologna und Theodoli, die das unstimmige Proportionsverhältnis zu den kleinteiligen restlichen Miniaturen kritisierten. Unter Berufung auf die Autorität des Marchese, dessen buon gusto Bologna wiederholt hervorhob ${ }^{92}$, lehnte der maggiordomo das bereits fertige Relief und damit das Konzept Fontanas $a b^{93}$; stattdessen gab er eine filigrane Kopie von Michelangelos „Jüngstem Gericht“ in Auftrag ${ }^{94}$.

Da Maurizio Bologna die figure grandi bemängelte, ist es unwahrscheinlich, dass Fontana ein „Jüngstes Gericht“ vorgesehen hatte, das ja zwangsläufig figurenreich und damit kleinteilig ist. Im Palazzo Colonna existiert, eingelassen in einen Betstuhl, eine großfigurige elfenbeinerne „Grablegung", die ein Gemälde Federico Baroccis kopiert und stilistisch durchaus den Gebrüdern Stainhart zuzuweisen sein könnte (Abb. 13) ${ }^{95}$. Wie das Zentralrelief des Kunstschranks besitzt jenes Werk einen halbkreisförmigen oberen Abschluss und wird bekrönt von einem breit ausladenden Dreiecksgiebel (in dem Gottvater und Engel auf Wolken erscheinen). Die Vermutung liegt nahe, dass es sich dabei um das verworfene, einst für den Kabinettschrank vorgesehene Mittelstück handelt. Wenn dem so ist, än-

${ }^{91}$ Dokument 10.

92 Dokument 3,4 und 7 .

93 Dokument 6 und 10.

${ }^{94}$ Siehe oben Anm. 43: Die Zahlungen für das „Jüngste Gericht“ begannen bereits am 15. September 1679, d. h. zwei Wochen bevor Lorenzo Onofrio Colonna überhaupt über den Programmwechsel informiert wurde.

95 H. Olsen, Federico Barocci. Kopenhagen 1962, 169-172; vgl. Safarik (wie in Anm. 4), 190. 

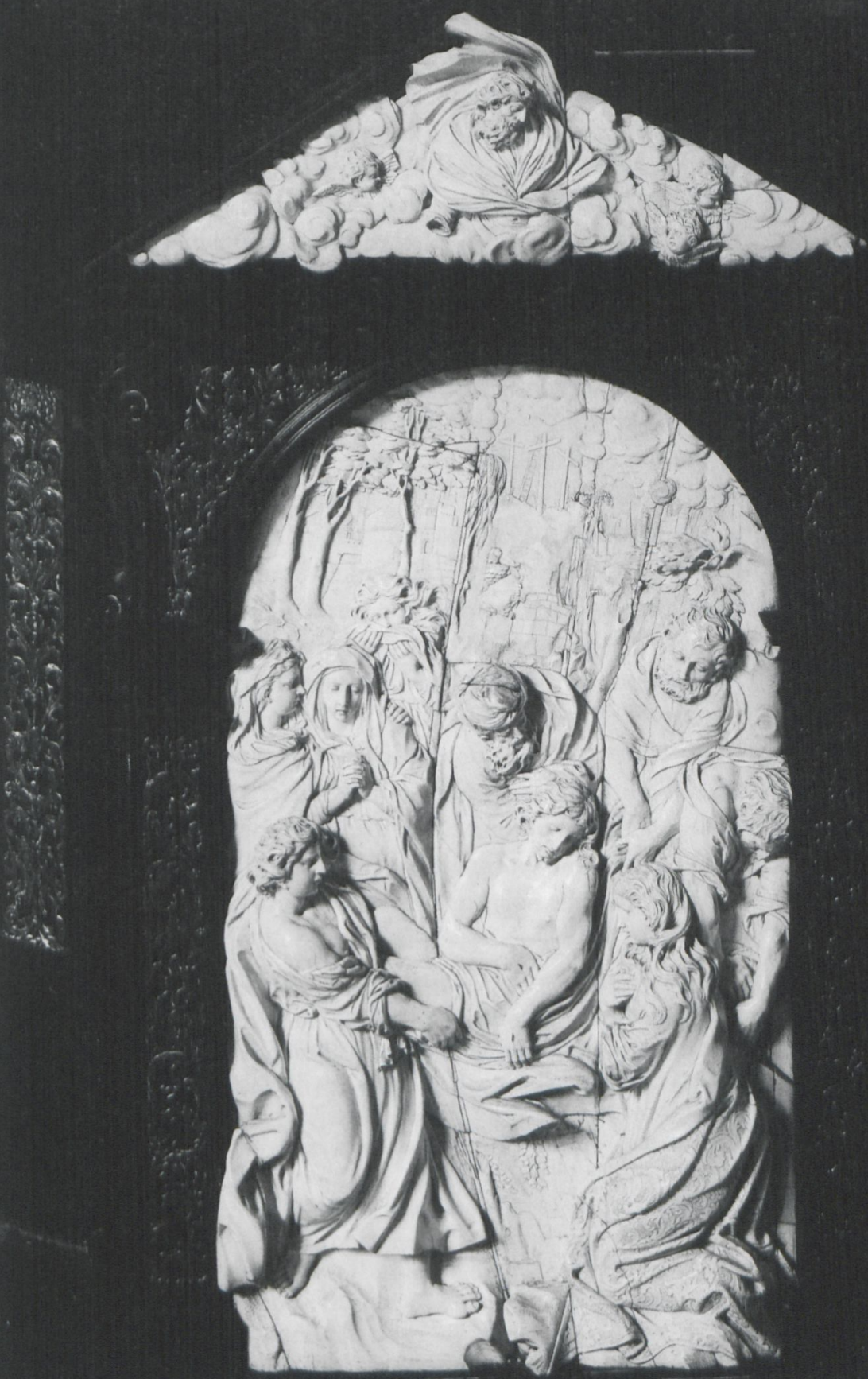

Abb. 13: Rom, Palazzo Colonna: „Grablegung“ (Franz und Dominik Stainhart?) 
derte Maurizio Bologna (bzw. sein Berater) nicht nur das Thema des zentralen Reliefs, sondern nahm auch eine neue kunsthistorische Akzentuierung vor, indem er ein kanonisches Werk des Cinquecento ein Ensemble dominieren ließ, das primär auf Künstler des Seicento ausgerichtet war ${ }^{96}$ (Barocci, Cortona $^{97}$, Lanfranco ${ }^{98}$, Schor ${ }^{99}$, Algardi ${ }^{100}$, Rubens ${ }^{101}$ ).

Eine „Grablegung“ wäre ursprünglich im Zentrum des Bildprogramms zweifellos gut am Platz gewesen, da etliche der am Mittelrisalit des Schrankes angebrachten Reliefs sich auf die Vita Christi beziehen (vgl. Abb. 2): „Anbetung der Hirten“, „Bethlehemitischer Kindermord“, die bereits diskutierte „Kreuztragung“ und eine „Auferstehung“ hätten die "Grablegung" sinnvoll umrahmt. Auch die schräg rechts über dem Dreiecksgiebel platzierte „Kreuzesvision Konstantins“ passt in den Kontext, denn so wie der Gekreuzigte über Sünde und Tod triumphierte, so siegte Konstantin im Zeichen des Kreuzes über die Ungläubigen. Das „Jüngste Gericht“, das später (anstelle der „Grablegung“?) die zentrale Position einnahm, verschob die Akzente ein wenig: Zwar ist auch dabei Christus der Protagonist, doch eher als Herrscher denn als Heilsbringer. Als das letzte Erscheinen des Herrn am Ende der Welt kann das ,„Jüngste Gericht" mit der „Anbetung der Hirten“ (seinem ersten Erscheinen in der Welt) und der „Kreuzesvision“ (der Erscheinung seines Siegeszeichens) in Beziehung gesetzt werden ${ }^{102}$.

Die einzigen Schnitzereien, die aus der theologischen Thematik des Mittelrisalits herausfallen, sind die oben besprochenen antiken Historien nach Fresken Pietro da Cortonas (Abb. 9a und 9c). Beide präsentieren tugendhafte Herrscher, die der Versuchung durch weibliche Schönheit widerstehen ${ }^{103}$. Insgesamt sechs solcher Szenen finden sich über den ge-

96 Es wäre zu überlegen, ob die Themen der drei Reliefs, die auf Fresken der Raffaelschen Loggien rekurrieren, auch erst in diesem letzten Schritt der Programmgestaltung ausgewählt wurden. Es handelt sich um „Die Erschaffung der Tiere“ (vgl. N. Dacos, Le logge di Raffaello. Maestro e bottega di fronte all'antico. Roma ${ }^{2}$ 1986, Tav. XI), „Die Erschaffung Evas“ (ibid., Tav. XII) und den „Sündenfall“ (ibid., Tav. XIII). Auf das Vorbild der Loggien verwies bereits - ohne Nennung von Beispielen - Kessler (wie in Anm. 11), 51.

$97 \mathrm{Vgl}$. Anm. 104, 107 und 109.

$98 \mathrm{Vgl}$. Anm. 89.

99 Vgl. Anm. 141 und 142.

$100 \mathrm{Vgl}$. Anm. 107.

101 Vgl. Dokument 14.

102 Sinnvollerweise wurden die beiden Hochformate „Anbetung der Hirten“ und „Kreuzesvision“ als Pendants angebracht (über den gekuppelten Säulen des Mittelrisalits).

103 Campbell (wie in Anm. 85), 100-104. 
samten Schrank verteilt, freie Kopien nach den Lünettenfresken in der „Sala di Venere" des Florentiner Palazzo Pitti" ${ }^{104}$.

Die "Sala di Venere" bildet den Auftakt einer Raumfolge, in der das gemalte alter ego des Fürsten eine Art ,Bildungsroman' durchlebt. Das zentrale Deckenbild des ersten Saales zeigt, wie Minerva den jungen Helden den Armen der Venus entreißt. Die Lünettenfresken ergänzen dies durch historische Exempla tugendhaften Verhaltens, das sich durch Triebkontrolle und Widerstand gegen die Verlockungen der Venus auszeichnet. Die Fresken der nächsten Räume schildern, wie der Protagonist von Apoll und den Musen unterwiesen wird (,Sala di Apollo“), wie er sich in einer Seeschlacht bewährt („Sala di Marte“) und wie er am Ende seines Lebens den verdienten Lohn für seine heroischen Taten empfängt (,,Sala di Giove", „Sala di Saturno") $)^{105}$.

Interessanterweise handelte es sich auch bei dem westlichen Anraum der Galleria Colonna, für den der Kabinettschrank wohl konzipiert wurde, um eine „Sala di Venere“: 1676 wurden Statuennischen gemauert und vier überlebensgroße Venusfiguren angeliefert. ${ }^{106}$ Ähnlich wie im Palazzo Pitti liegt dieser Raum vor einem Saal, der einen heldenhaften Sieger bzw. Marcantonio Colonnas Triumph über die ,Ungiäubigen' (Türken) in der Seeschlacht von Lepanto feiert. Das Programm des Kabinettschranks bildet dazu gewissermaßen ein ,Präludium‘: Die sechs auf den Lünettenfresken der Florentiner „Sala di Venere“ basierenden Szenen, welche die Überwindung niederer Triebe als Voraussetzung hehrer Taten thematisieren, verbinden sich durchaus sinnvoll mit den religiösen Reliefs, die die Grundlagen des christlichen Glaubens und damit die Legitimation für den Kampf gegen die Osmanen veranschaulichen.

Einige weitere Schnitzereien auf den Seitenteilen des Schrankes gehören in diesen Kontext: Da sind zum einen Kampfszenen und Reiterschlachten, zum anderen Heiligenbilder mit militärischen Untertönen. Ein Relief stellt die Bekehrung des militanten Christenverfolgers Saulus dar, der später als Paulus zum Missionar werden sollte; ein anderes zeigt, wie der bereits bekehrte Soldat Sebastian für seinen Glauben das Marty-

${ }^{104}$ Ibid., 91-108, Abb. 34-41. Die vier weiteren, ohne erkennbare Systematik über die Seitenfelder des Schranks verteilten Kopien nach Fresken der „Sala di Venere“ sind: „Antiochus und Stratonice“, „Augustus und Cleopatra“, „Cyrus und Panthea" sowie „Die Enthaltsamkeit des Scipio“ (vgl. Abb. 2).

105 Campbell (wie in Anm. 85), 144-157, speziell $147 \mathrm{f}$.

${ }^{106}$ Diese später wieder zerstörte Dekoration lässt sich aus den Baudokumenten rekonstruieren; siehe STRUNCK (wie in Anm. 21). Ein Inventar von 1679 verzeichnet quattro Venere di marmo bianco alte palmi dieci in circa als einzige Kunstobjekte in der noch unfertigen Galerie (III. QB. 16, fol. 311). 
rium erleidet. Der schon erwähnten „Kreuzesvision Konstantins“ steht „Die Vertreibung Attilas durch Leo den Großen“ gegenüber: In beiden Fällen geht es um die Zurückschlagung der Ungläubigen mittels himmlischen Beistands ${ }^{107}$.

Wohl nicht zufällig erinnert die Miniatur-Architektur des Kabinettschranks an eine Kirchenfassade und zitiert im Mittelrisalit das klassische Tempelfront-Motiv ${ }^{108}$, verleiht so den Exempla antiker Tugend und christlicher Religiosität einen würdevollen Rahmen. Unterworfene, mit Fußeisen gefesselte Mohren tragen diesen den abendländischen Idealen geweihten Schrein und blicken staunend zu dem Wunderwerk einer, überlegenen' Kultur empor. Ihre dienende Präsenz und die zwischen ihnen aufgerichteten Militärtrophäen machen die glaubenskriegerische Thematik in besonderer Weise evident (Abb. 2).

Es sei jedoch nicht verschwiegen, dass sich nicht alle Reliefs nahtlos in das hier skizzierte Programm einfügen. Die Geschichte Coriolans ist beispielsweise gerade kein Tugendexempel, sondern veranschaulicht umgekehrt, wie ein Mann sich durch Frauen beeinflussen lässt und dafür mit dem Leben bezahlt - ein abschreckendes, warnendes Beispiel ${ }^{109}$. „Artemisia begutachtet ein Projekt für das Grab des Mausolos" thematisiert ebenfalls das Geschlechterverhältnis, stellt aber keine gefährlich verführerische, sondern eine tugendhafte Frau in den Mittelpunkt ${ }^{110}$. Während

${ }^{107}$ Das Relief der „Kreuzesvision“ geht letztlich auf die vatikanische „Sala di Costantino" bzw. auf Raffael und Giulio Romano zurück, gibt aber nur einen Teil der Komposition wieder und steht somit einem Teppichkarton Pietro da Cortonas näher, der denselben Ausschnitt wählte. Vgl. M. Rohlmans, Leoninische Siegverheißung und clementinische Heilserfüllung in der Sala di Costantino. Zeitschrift für Kunstgeschichte 57 (1994), 153-169; Pietro da Cortona e il disegno, hrsg. von S. Prosperi Valenti Rodinò. Milano 1997, 96f. (mit Abb.). Die „Zurückweisung Attilas" gehört zwar ebenfalls zu den von Raffael in den vatikanischen „Stanzen“ dargestellten Themen, doch arbeiteten die Gebrüder Stainhart in diesem Fall nicht nach einem malerischen, sondern nach einem skulpturalen Modell, nämlich nach Algardis Marmorrelief in St. Peter. Siehe dazu R. Premesberger, Eine Peripetie in Stein? Bemerkungen zu Alessandro Algardis Relief der Begegnung Leos des Großen mit Attila, in: Festschrift für Hermann Fillitz zum 70. Geburtstag (Aachener Kunstblätter 60), Köln 1994, 397-416.

108 Siehe unten Abschnitt III.

${ }^{109}$ Auf die Vorlage dieses Reliefs, eine von Ciro Ferri gestochene Zeichnung Pietro da Cortonas, machte mich dankenswerterweise Jörg Martin Merz aufmerksam. Siehe P. Dreyer, Kupferstichkabinett Berlin. Italienische Zeichnungen. Stuttgart-Zürich 1979, Kat. Nr. 53; J. M. Merz, Pietro da Cortona und sein Kreis. Die Zeichnungen in Düsseldorf (im Druck).

${ }^{110}$ Die Wahl dieser Szene scheint von einer Tapisserie der Sammlung Colonna angeregt worden zu sein: vgl. SAFARIK (wie in Anm. 4), 263, Abb. 463. 
manche alttestamentarischen Szenen noch einen Bezug zur Tugendthematik besitzen (so der „Sündenfall“ bzw. „Die Arche Noah“ als Hinweis auf die Bestrafung der Sünde durch die Sintflut), besteht in anderen Fällen keine erkennbare Verbindung zu den geschilderten Hauptideen (etwa bei „Die Erschaffung der Tiere“). Ferner verblüfft die unsystematische Verteilung der Bildwerke: So befindet sich die Schöpfungsszene ganz rechts unten, der „Sündenfall“ schräg darüber, „Die Arche Noah“ weitere zwei Reihen höher (vgl. Abb. 2). Alle Themengruppen sind wild gemischt, weder eine chronologische noch eine inhaltliche Ordnung lässt sich auf den Seitenfeldern des Schrankes erkennen. Dies ist wohl auf die oben geschilderte sukzessive Programmgenese zurückzuführen: Da Lorenzo Onofrio Colonna die Auswahl etlicher Szenen verschiedenen Beratern überließ und da der Schrank erst Jahre nach Beginn der Arbeiten zusammengebaut wurde, scheint das Verständnis für das ursprünglich angelegte Programm allmählich verloren gegangen zu sein.

\section{III}

Das in Abschnitt I vorgestellte Dokumentenmaterial belegt, dass an dem besprochenen Kunstschrank (Abb. 2) beinahe ebenso lange gearbeitet wurde wie an der Galerie selbst. Zahlungen für die Reliefs setzten bereits im Frühjahr 1675 ein, was die Bestellung des Schrankes in unmittelbare zeitliche Nähe zu Berninis neuem Galeriekonzept rückt ${ }^{111}$. Das wirft die Frage auf, ob der Meister auch beim Entwurf des ungewöhnlichen Einrichtungsstücks eine Hand im Spiel gehabt haben könnte - bekanntlich war er sich ja keineswegs zu schade dafür, Möbel zu gestalten ${ }^{112}$. Im Folgenden möchte ich die These vertreten, dass das Projekt als Ganzes von Bernini konzipiert wurde, er dann jedoch die Ausführung an Carlo Fontana delegierte, von dem zweifelsfrei die 1677 entworfene und ab 1680 realisierte Miniatur-Architektur des Schrankes stammt.

${ }^{111}$ Siehe oben, Anm. 9, 10 und 12.

112 A. Gonzalez-Palacios, Bernini as a Furniture Designer. The Burlington Magazine 112 (1970), 719-722; DERs., Bernini e la grande decorazione barocea, in: Gian Lorenzo Bernini. Regista del Barocco, hrsg. von M. G. Bernardini-M. Fagiolo DELl'Arco. Milano 1999, 185-192; S. WALKER, The Artistic Sources and Development of Roman Baroque Decorative Arts, in: Life and the Arts in the Baroque Palaces of Rome. Ambiente Barocco, hrsg. von S. Walker-F. Hammond. New Haven-London 1999, 2-19. M. Fagiolo dell'Arco, Berniniana. Novità sul regista del Barocco. Milano 2002, 147-156.

113 H. Hager, Carlo Fontana, in: Storia dell'architettura italiana. Il Seicento, hrsg. von A. Scotti Tosini. Milano 2003, 238-261, hier 240-246. 
Obwohl Carlo Fontana 1680 bereits auf eine über zwanzigjährige professionelle Aktivität zurückblicken konnte, glückte ihm der eigentliche Durchbruch erst nach dem Tod seines Lehrmeisters Bernini. Die siebziger Jahre waren für ihn eine schwierige Periode, in der sich seine Projekte in recht bescheidenem Rahmen hielten bzw. in etlichen Fällen unrealisiert blieben ${ }^{113}$. 1673/74 musste er sich massive Korrekturen Berninis an seinem Entwurf für Santa Maria di Montesanto gefallen lassen ${ }^{114}$, und 1675 gehörte er noch nicht zu jenen Mitgliedern der Accademia di San Luca, die eigene Schüler ausbildeten ${ }^{115}$.

Im Sommer 1674 lieferte Bernini den, Masterplan ' für eine tiefgreifende Umgestaltung der Galleria Colonna: Der bestehende Galerieraum wurde an seinen beiden Stirnseiten durch großzügige, von Kolossalsäulen abgestützte Durchgänge zu zwei quadratischen Salons hin geöffnet, von denen der erhöhte östliche Anraum als ,Thronsaal', der westliche hingegen als Vestibül dienen sollte (Abb. 1). Die aufwändige Realisierung des Projekts begann im Frühjahr $1675^{116}$, d. h. genau parallel zur Entstehung der ersten Reliefs für jenen Schrank, der heute den westlichen Anraum der Galerie schmückt. Dass Bernini sich nicht nur für die Architektur, sondern auch für die Ausstattung der Galleria Colonna interessierte, belegt eine Nachricht, der zufolge er am 7. Mai 1675 die im Entstehen begriffenen Deckenfresken begutachtete. Da die Fresken streckenweise als ,gemalter Kommentar' zur neuen Galeriearchitektur gelesen werden können, wäre es sogar denkbar, dass Bernini - wie für mehrere seiner Projekte überliefert - auf das Bildprogramm direkten Einfluss nahm ${ }^{117}$.

Ungleich bescheidener war in jenen Jahren Carlo Fontanas Rolle im Palazzo Colonna. Seine früheste Erwähnung in den Rechnungsbüchern betrifft unter dem Datum 10. März 1674 zwei Bilderrahmen: due cornici longhe di sorba per dissegno del Carlo Fontana ${ }^{118}$. Im Juli 1674 schrieb Fontana eigenhändig eine Misura e stima über den Bau eines pozzo per

114 H. Hager, Zur Planungs- und Baugeschichte der Zwillingskirchen auf der Piazza del Popolo: S. Maria di Monte Santo und S. Maria dei Miracoli in Rom. Römisches Jahrbuch für Kunstgeschichte 11 (1967/68), 189-306, hier 240-249, 291f.

${ }^{115}$ G. Bonaccorso, I luoghi dell'architettura: lo studio professionale di Carlo Fontana, in: Roma, le case, la città, hrsg. von E. Debenedetrı. Roma 1998, 95-125, hier 100 .

116 Strunck, Lorenzo Onofrio Colonna (wie in Anm. 3), $572 \mathrm{f}$.

117 Ibid., 572, 577.

118 Rechnung von Giacomo Herman Ebanista für Arbeiten ab 27. Januar 1673 (in I. A. 56).

${ }^{119}$ Misura e stima vom 18. Juli 1674 (in I. A. 57). 


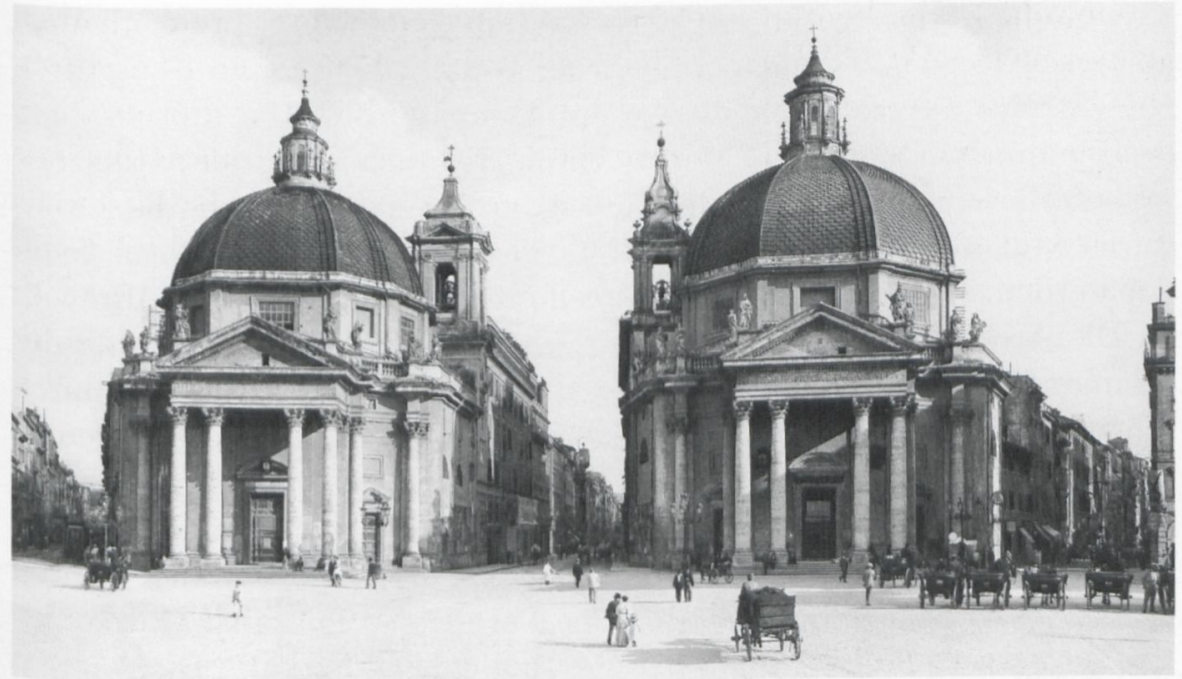

Abb. 14: Rom, Piazza del Popolo, Blick auf die 'Zwillingskirchen'

uso di $g[\mathrm{~h}]$ iaccio nel giardino verso Monte Cavallo; diese höchst unbedeutende Arbeit wurde dann auch noch von dem Colonna-Hausarchitekten Antonio del Grande überprüft und gönnerhaft mit einem considerato sta bene kommentiert ${ }^{119}$. Dokumente von Ende 1675 bzw. Anfang 1676 bezeugen Fontanas Mitwirkung am Bühnenbild der im Palazzo Colonna aufgeführten Oper La prosperità di Elio Sejano ${ }^{120}$. 1676 taxierte er die Stuckdekoration eines Raumes im Sommerappartement ${ }^{121}$, und 1677 lieferte er schließlich den Entwurf, nach dem ab 1680 der ElfenbeinPrunkschrank zusammengebaut wurde ${ }^{122}$.

Coudenhove-Erthal sah die Architektur jenes Schranks als Reflex auf die ,damals eben vollendete [Fassade] von S. Maria dei Miracoli, so insbesondere in der mittleren Giebellösung " $(\text { Abb. 14) })^{123}$. Mindestens ebenso deutlich sind jedoch Elemente der zwischen 1682 und 1684 ausgeführten Fassadengestaltung von S. Marcello vorweggenommen (Abb. 15): Die für Fontana charakteristischen „Giebelbekrönungen mit ihren stark gekrümmten Segmentfragmenten und den postamentartigen Erhebungen,

\footnotetext{
${ }^{120}$ Tamburini (wie in Anm. 7), 130-133.

${ }^{121}$ Misura e stima vom 1. Juni 1676 (in I. A. 57).

${ }^{122}$ Siehe oben, Anm. 55-58.

${ }^{123}$ Coudenhove-Erthal (wie in Anm. 4), 50. Eine detaillierte Erörterung der Baugeschichte der beiden ,Zwillingskirchen' an der Piazza del Popolo bei Hager (wie in Anm. 114).
} 
die zwischen ihnen aufsteigen" ${ }^{124}$, finden sich sowohl am Schrank als auch an jener Kirche und dienen in ähnlicher Weise als Sockel für Skulpturen bzw. für das nie realisierte quadro des Tympanons ${ }^{125}$. Die Aufsockelung der gekuppelten Säulen auf Postamenten, die Ausbildung der Attikazone und die Betonung der Fassadenränder durch Vertikalachsen, die jeweils durch Säulen bzw. Pilaster und eine darüber angeordnete Skulptur gebildet werden, stehen ebenfalls S. Marcello näher als S. Maria dei Miracoli.

Die Architektur beherrscht zwar in der Fernsicht die Wirkung des Prunkmöbels, bildet aber doch nur den Rahmen für die Reliefs, die durch Kostbarkeit des Materials und Delikatesse der Ausführung das eigentliche Objekt von meraviglia sind ${ }^{126}$. Wenn bereits die generelle Dominanz der Skulptur nicht unbedingt auf den Architekten Fontana als Urheber des Projekts deutet, so sprechen insbesondere die monumentalen Mohren gegen dessen Autorschaft, da sie keine Parallele in Fontanas Euvre finden. In diesem Sinne urteilte bereits Coudenhove-Erthal: „Die Aufstellung von Bronzen [als Bekrönung des Kunstschranks] mag von Fontana in Analogie zu den Statuen an der Kirchenfassade [von S. Maria dei Miracoli] vorgesehen gewesen sein, keinesfalls aber in der bestehenden Anordnung, die seinem Stildenken durchaus widerspricht. Auch der von Atlanten getragene Untersatz, auf dem der Schrank steht, entstammt kaum der Erfindung Fontanas"127. Jene Mohren (Abb. 2) sind Meisterwerke, den puppenhaften Figuren des Philipp Schor und den apathischen Orientalen unter den Konsoltischen der Galerie meilenweit überlegen (vgl. Abb. 4, 6, 7): vollrunde, bewegte, lebendige Skulpturen.

Die Idee, Atlanten bzw. Karyatiden aus der Architektur in das Kunsthandwerk zu übersetzen, war zweifellos nicht neu. Etliche Möbel des 17. Jahrhunderts ruhen auf menschenähnlichen Stützfiguren ${ }^{128}$. Die Mohren und Orientalen, die das kunsthandwerkliche Leitmotiv in der Galleria Colonna bilden, sollten wohl auf die Unterwerfung der ,Ungläu-

${ }^{124}$ Hager (wie in Anm. 114), 224.

125 Zur Fassade von S. Marcello vgl. Hager (wie in Anm. 113), 246.

${ }^{126}$ Im Inventar von 1714 werden die Elfenbeinreliefs als lavorati à meraviglia bezeichnet. SAFARIK-PuJa (wie in Anm. 2), 283f., Nr. 564.

127 Coudenhove-Erthal (wie in Anm. 4), 50.

${ }^{128}$ Um nur einige Beispiele zu nennen: Lizzani (wie in Anm. 4), Abb. 7, 98, 99, 101, 102, 105, 107, 108; A. Gonzalez-Palacios, Il Tempio (wie in Anm. 4), II, Abb. 86, 96, 121-126, 133, 386, 388; DERs., Il Tempio del Gusto. Le arti decorative in Italia fra classicismi e baroceo. Il granducato di Toscana e gli stati settentrionali. Milano 1986, II, Abb. 3, 5, 7-15, 19, 22, 705, 735; DERs., Il Gusto dei Principi. Arte di corte del XVII e del XVIII secolo. Milano 1993, II, Abb. 21; WALKER (wie in Anm. 112), 2 (Abb.). 


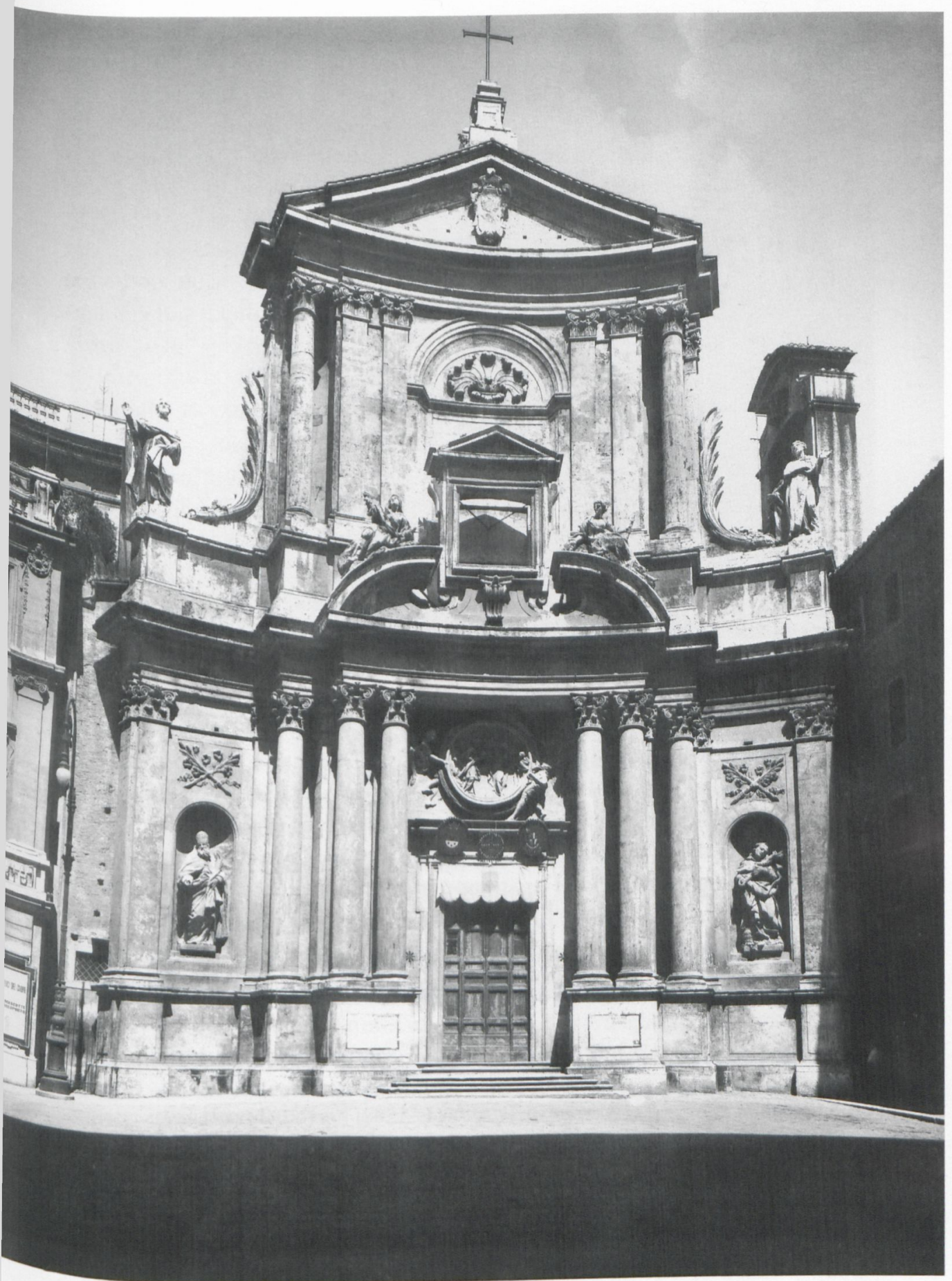

Abb. 15: Rom, S. Marcello al Corso, Fassade 


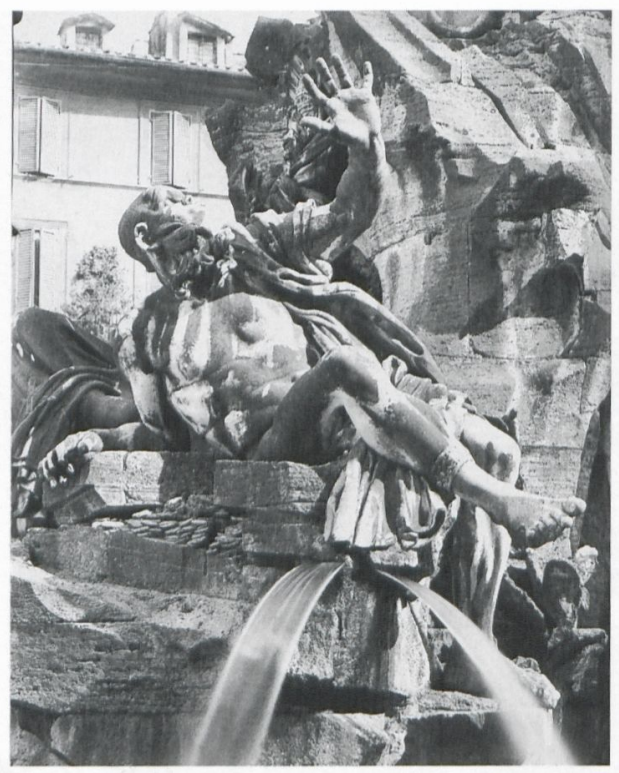

Abb. 16: Rom, Piazza Navona, Vierströmebrunnen, Detail: „Rio de la Plata“ (nach

Entwurf von Gianlorenzo Bernini)

bigen' bzw. auf den in den Galeriefresken verherrlichten Sieg über die Türken bei Lepanto anspielen, auf den sich die Colonna viel zugute hielten. Auch wenn also der Gedanke, Mohren als Stützfiguren für den ElfenbeinPrunkschrank zu wählen, von der Auftragssituation und vom Material (Ebenholz) nahe gelegt wurde und an sich nicht übermäßig innovativ war ${ }^{129}$, unterscheidet sich doch die Behandlung dieses Motivs deutlich von früheren Kunstmöbeln ${ }^{130}$ bzw. von Philipp Schors, konkurrierendem ' Schrankuntersatz (Abb. 4): Die Mohren stehen in einem realistischen Größenverhältnis zum Schrank, wirken nicht wie putzige Abbreviaturen bzw. wie aus Laubwerk hervor gewachsene Arabesken, sondern wie echte Träger.

Der linke Schrankträger erinnert in der Drehung des Kopfes, dem erstaunten Aufschauen, der Armhaltung und der expressiven Geste seiner linken Hand an den Rio de la Plata von Berninis Vierströmebrunnen (Abb. 16). Und so, wie dort auf den Rio de la Plata symmetrisch die Donau bezogen ist, die das Papstwappen mit sorgendem Gestus aufrichtet $^{131}$, so antwortet auf den linken Mohren die rechte Stützfigur, die behutsam zum Schrank empor greift. Ähnlich wie der Vierströmebrunnen (nur natürlich in reduzierter Form) zielt die Gestaltung des Schrankun-

129 Spätestens ab 1670 gab es im Palazzo Colonna bereits einen Tisch, der von einem ,Sklaven' getragen wurde, wie aus einer Rechnung des Vergolders Basilio Honofrij unter dem Datum 22. November 1670 (in I. A. 62) hervorgeht: per haver messo di Rame à mordente à olio un piede d'una tavola di pietra che la detta Tavola è sostenuta da un Schiavo, che sono indorati tutti $i$ suoi panni, et il rimanente della figura tutto di Rame, coloritoci il suo piedestallo finta di pietra di porfido, con havervi messo d'oro due Cocchiglie, che stanno sul detto piano, et altro (scudi 10:00).

${ }^{130}$ Man vergleiche die in Anm. 128 genannten Beispiele.

${ }^{131}$ R. WitTkower, Bernini. The Sculptor of the Roman Baroque. London ${ }^{4} 1997,224$, Abb. 184. Zum Brunnen siehe R. Preimesberger, Obeliscus Pamphilius. Beiträge 


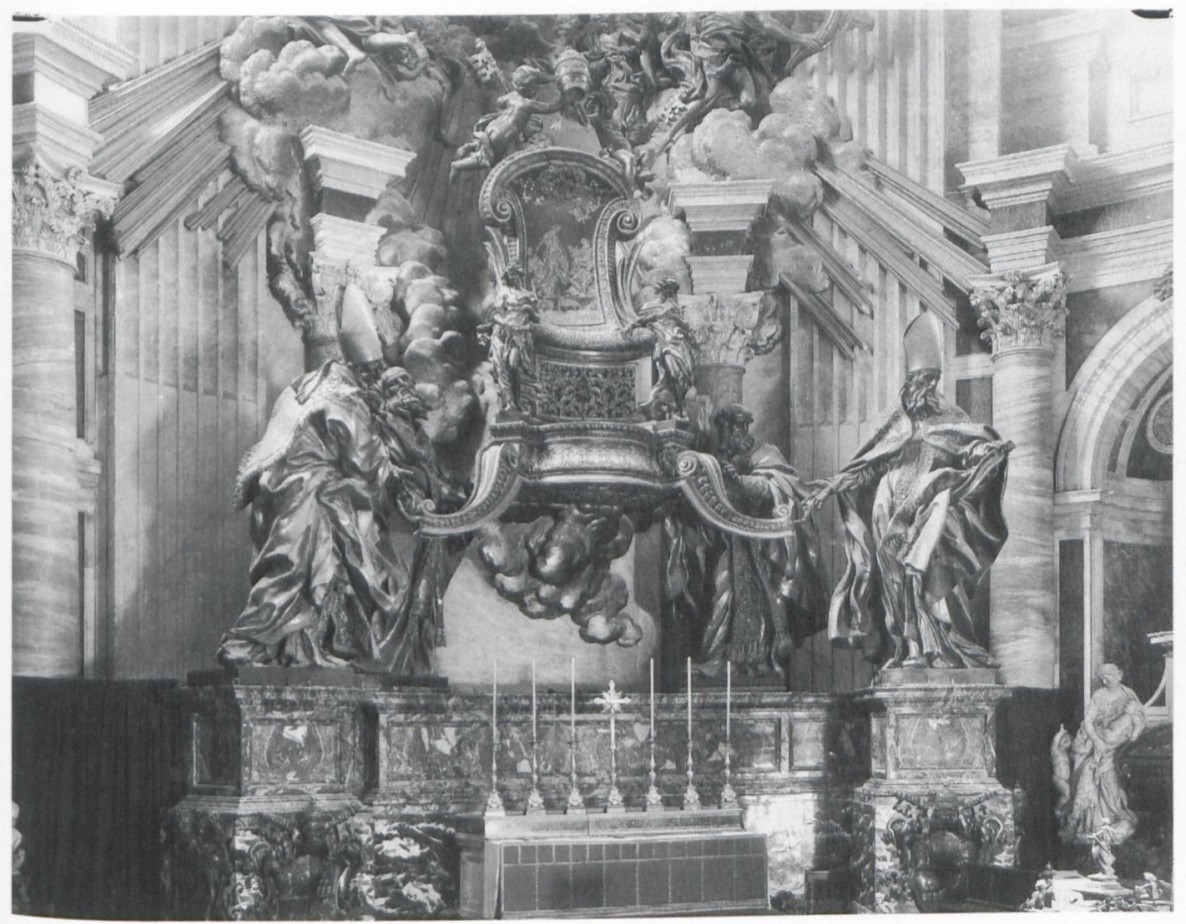

Abb. 17: Rom, Petersdom: „Kathedra Petri“ (nach einem Entwurf von Gianlorenzo Bernini)

tersatzes darauf ab, Staunen über die Stabilität einer höchst instabil erscheinenden Konstruktion zu erzeugen. So wackelig wie der Obelisk auf dem ausgehöhlten Felsen wirkt auch der massive Schrank auf den Schultern der Träger, die ihn kaum berühren.

Merkwürdigerweise fassen die beiden ,Träger" die Last auf ihren Schultern gar nicht an. Ihre Hände verharren kurz vor den Ecken des Schrankes, als ob sie diese gerade losgelassen hätten, aber jederzeit bereit wären, wieder zuzupacken, sollte sich die Balance als instabil erweisen. Das altbekannte Atlantenmotiv wird hier überraschend variiert: Halten die beiden das Gewicht überhaupt aus? Kippt der Schrank? Der fragen-

zur Vorgeschichte und Ikonographie des Vierströmebrunnens auf der Piazza Navona. Münchner Jahrbuch der bildenden Kunst 25 (1974), 77-162 sowie jüngst I. Herкцотz, Eine zeitgenössische Beschreibung von Berninis Vierströmebrunnen nebst einem Plädoyer für eine publikumsorientierte Kunstwissenschaft, in: Opus Tessellatum. Modi und Grenzgänge der Kunstwissenschaft. Festschrift für Peter Cornelius Claussen, hrsg. von K. Corsepius-D. Mondini-D. Senekovic-L. SibiLLano-S. Vitali. Hildesheim u. a. 2004, 411-429. 
de Blick und die angespannte Geste des linken Mannes laden den labilen, flüchtigen Moment mit Dramatik auf, überführen das simple Stützen einer Last in die Erzählung einer Handlung mit ungewissem Ausgang. Genau diese Dynamisierung von Stützfiguren bildet ein wichtiges Kennzeichen des Bernini'schen Schaffens ${ }^{132}$.

Wie Matthias Winner gezeigt hat, beschäftigte das Verhältnis von Stütze und Last den Bildhauer Bernini lebenslang und inspirierte ihn immer wieder zu neuen Gestaltungsideen ${ }^{133}$. Der Untersatz des ColonnaSchrankes steht in diesem Punkt vor allem Berninis Kathedra Petri (Abb. 17) nahe, weil dort ebenfalls das Nicht-Tragen thematisiert ist: Beide Kunstwerke lenken durch die Hände der "Träger', die das Objekt gar nicht bzw. nur flüchtig berühren, das Interesse des Betrachters auf die Frage, wie der Künstler das statische Problem bewältigte.

Filippo Baldinucci überlieferte die folgende lehrreiche Anekdote aus Berninis Jugend: Wann immer der Knabe seinem Vater Pietro eine Arbeit vorlegte, lobte dieser sie zwar, behauptete aber gleichzeitig, dass Gianlorenzo die nächste Aufgabe sicher nicht ebenso gut bewältigen werde - was den Sohn anstachelte, es um so besser zu machen. Der kluge Vater regte den jungen Künstler auf diese Weise an, sich ständig mit sich selbst zu messen: tenevalo con se medesimo in continovo cimento $^{134}$. Auch in späteren Jahren blieb Gianlorenzo jenem ,paragonalen` Schaffensprinzip treu. Immer wieder trat er gewissermaßen mit sich selbst in Wettstreit, um eine bestimmte Idee weiterzuentwickeln und zu perfektionieren. Der wiederholte, stets der speziellen räumlichen Situation angepasste Gebrauch eines auszeichnenden Doppelsäulenmotivs ${ }^{135}$ ist hierfür ebenso ein Beispiel wie die konzeptionelle Verwandtschaft zwischen der Cappella

132 „Atlantids grimacing under the load of tables or stands" sind laut WALKER (wie in Anm. 112), 4 ein Zeichen für Berninis „decisive impact on decorative arts“, da sie seine Vorliebe für ,dramatic staging “ aufgreifen.

133 Die Autorin bezieht sich hier auf Professor Winners Führung durch die BerniniAusstellung in der Villa Borghese (25. Mai 1998), in der er speziell das Thema tronco in den Mittelpunkt stellte. In seinem Katalogbeitrag kommen die dabei geäußerten Ideen nur teilweise zur Sprache: M. Winner, Ratto di Proserpina, in: Bernini Scultore. La Nascita del Baroceo in Casa Borghese, hrsg. von A. Coliva-S. Schutze. Roma 1998, 180-203. Siehe auch R. Wiтtкower, The Vicissitudes of a Dynastic Monument: Bernini's Equestrian Statue of Louis XIV, in: De Artibus Opuscula XL. Essays in Honor of Erwin Panofsky, hrsg. von M. Meiss. New York 1961, I, 497-531, hier 505.

134 Vita di Gian Lorenzo Bernini scritta da Filippo Baldinucei con l'inedita vita del Baldinucei scritta dal figlio Franceseo Saverio, hrsg. von S. Samek Ludovicı. Milano 1948,75 .

${ }^{135}$ STrunck, Lorenzo Onofrio Colonna (wie in Anm. 3), 568, 573f. 
Cornaro, der Chigi-Kapelle in S. Maria del Popolo und dem Alexandergrab in St. Peter ${ }^{136}$. In diesem Sinne könnte auch der Colonna'sche Galerieschrank ein augenzwinkerndes, Selbstzitat‘ Berninis sein, ein kreativer Transfer von Motiven der Kathedra und des Vierströmebrunnens in einen ganz andersartigen Kontext.

Franz und Dominik Stainhart, die 1674 oder Anfang 1675 nach Rom gekommen waren, um dort ihre Kunst der Bildschnitzerei zu vervollkommnen, wollten sicher den berühmtesten Bildhauer ihrer Epoche so bald wie möglich kennen lernen. Als idealer Vermittler bot sich der deutschsprachige Schor-Clan an, der über beste Kontakte zu Bernini verfügte $^{137}$ und außerdem selbst viel auf dem Gebiet der Skulptur arbeitete $^{138}$. Johann Bernhard Fischer (,von Erlach') war genau in jenen Jahren in Philipp Schors Werkstatt damit beschäftigt, dessen Entwürfe skulptural umzusetzen ${ }^{139}$. Um die Schor dürfte eine ganze Galaxie von ,tedeschi gravitiert haben. Wohl nicht zufällig stammten die mit den Colonna-Galerieschränken befassten Kunsttischler Herman und Rues ebenso wie die Stainharts aus dem deutschen Sprachraum ${ }^{140}$ - vermutlich hatte Philipp Schor den Kontakt all jener Kunsthandwerker zu den Colonna eingefädelt.

${ }^{136}$ C. Strunck, Bellori und Bernini rezipieren Raffael. Unbekannte Dokumente zur Cappella Chigi in Santa Maria del Popolo. Marburger Jahrbuch fü Kunstwissenschaft 30 (2003), 131-182, hier 161, vor allem aber DIEs., Berninis Löwengrube. Eine neue Deutung der Cappella Chigi in Santa Maria del Popolo, in: Paragonales Denken, ästhetische Praxis und die Diversität der Sinne, hrsg. von H. BAADER-U. Muller-Hofstede-K. Patz-N. Suthor (im Druck).

137 SLADEK (wie in Anm. 20), 149, gibt einen Überblick über die Kooperation von Bernini und Johann Paul Schor (mit Bibliographie) und weist darauf hin, dass die beiden außerdem quasi Nachbarn waren: Bernini wohnte in der Via della Mercede, die Schor hatten ein Haus an der Piazza di Spagna. Hellmut Hager machte mich freundlicherweise auf die von Pascoli überlieferte Nachricht aufmerksam, Bernini habe bei sich zu Hause, Abendakademien' abgehalten, die natürlich den Kontakt mit verschiedensten Künstlern ermöglichten. (L. PAscoli, Vite de' pittori, scultori, ed architetti viventi dai manoscritti 1383 e 1743 della Biblioteca comunale „Augusta“ di Perugia. Treviso 1981, 235).

${ }^{138}$ Man denke etwa an Johann Paul Schors Mitarbeit an der Kathedra Petri, an seine Kutschenentwürfe, das Prunkbett für die Colonna, trofei da tavola, Reliquiare für die Cappella del Voto im Dom von Siena etc.: siehe den Werkkatalog bei Ehrlich (wie in Anm. 21).

${ }^{139}$ Siehe oben, Anm. 20.

${ }^{140}$ Der für den Corpus des studiolo d'avorio zuständige Ebanista Giacomo Herman dürfte identisch sein mit dem aus Richthofen gebürtigen Kunsttischler Jakob Hermann, der zwischen 1654 und 1677 den päpstlichen Hof belieferte, es dabei 
Es scheint nahe liegend, dass die Idee zum primär skulpturalen studiolo d'avorio in dem beschriebenen Kreis von Bildhauern und Kunsthandwerkern geboren wurde, ohne dass der Architekt Fontana anfänglich etwas damit zu tun gehabt hätte. Dies wird durch eines der Reliefs indirekt bestätigt. Es basiert auf Johann Paul Schors „Arche Noah“-Fresco, einem seiner künstlerischen Hauptwerke ${ }^{141}$. Obwohl das im Vergleich zum stark oblongen Fresco wesentlich kompakter proportionierte Relief die Komposition etwas ,strafft ${ }^{*}$, sind alle wesentlichen Bildelemente an analoger Stelle vertreten. Da meines Wissens kein Stich jenes Gemäldes existiert, stellt sich die Frage, nach welcher Vorlage die Gebrüder Stainhart arbeiteten. Wie oben bereits am Beispiel der „Kreuztragung“ deutlich wurde, fertigten die beiden selbst dann keine eigenen Zeichnungen an, wenn das mühelos möglich gewesen wäre. Im Fall von Schors Fresco kam erschwerend hinzu, dass sich dieses in der Galerie des päpstlichen Quirinalspalastes befand, d. h. wohl nicht ohne weiteres zugänglich war. Höchstwahrscheinlich konnten die Gebrüder Stainhart also auf Schors überaus sorgfältig ausgeführte, heute in Windsor Castle aufbewahrte Präsentationszeichnung zurückgreifen ${ }^{142}$ - was zumindest für eine enge Verbundenheit der Künstler, wenn nicht gar für direkte Werkstattzusammenhänge spricht.

Bezeichnenderweise nennt der Colonna-maggiordomo Maurizio Bologna als seine Berater in Sachen Kunstschrank u. a. Bernini und Philipp Schor, während er die Kompetenz Fontanas in Zweifel zieht ${ }^{143}$. Schor kommt allerdings als Entwerfer nicht in Betracht - zu sehr fallen seine eigenen kümmerlichen Orientalen gegen die vollplastischen Mohren des

zu erheblichem Wohlstand brachte und 1685 in Rom verstarb (siehe oben, Anm. 9). Zu Lorenzo Rues siehe oben, Anm. 24; NoAck (wie in Anm. 1), II, 502; WeIland (wie in Anm. 9), 740-742, 770; A. Tonnesmann-U. V. Fischer Pace, Santa Maria della Pietà. Die Kirche des Campo Santo Teutonico in Rom. Roma-FreiburgWien 1988, 87-91, 113f.

${ }^{141}$ Il patrimonio artistico del Quirinale. Pittura antica. La decorazione murale, hrsg. von L. Laureati-L. Trezzani. Roma 1993, 194 (mit Abb.), 196.

${ }^{142}$ A. Blunt-H. L. Cooke, The Roman Drawings of the XVII \& XVIII Centuries in the Collection of Her Majesty the Queen at Windsor Castle. London 1960, 110. Kat. Nr. 937; Fusconi 1985 (wie in Anm. 21), 160f., Abb. 1. Ein weiterer, noch näher zu überprüfender Bezug zum Euvre Johann Paul Schors besteht bei der Szene des „Heiligen Eustachius in der Löwengrube“ (vgl. Bibliotheca Sanctorum V. Roma 1964, Sp. 282): Dieselbe - seltene - Episode freskierte der Innsbrucker im Eustachius-Heiligtum bei Santa Maria della Mentorella, Guadagnolo (unpubliziert).

${ }^{143}$ Dokumente 10 und 14. 
studiolo d'avorio ab (Abb. 2, 4) ${ }^{144}$. Die Ähnlichkeit zwischen diesen Mohren und den ,Strömen' der Piazza Navona könnte vielmehr Berninis Federführung anzeigen. Berninis Anteilnahme an dem Projekt wird ferner daraus ersichtlich, dass er 1680 den Wert des zentralen Elfenbeinreliefs taxierte ${ }^{145}$.

Warum taxierte Bernini ausgerechnet das „Jüngste Gericht"? Aus dem simplen Grund, weil es sich um die größte, teuerste und wichtigste Schnitzerei handelte? Oder könnte er derjenige gewesen sein, der Maurizio Bologna dieses Thema vorgeschlagen hatte? Schließlich schrieb der maggiordomo ja: in quanto all'historie da farsi ne bassi rilievi mi son governato con i pareri del Signor Marchese Teodoli, Cavalier Bernino, Fitippo Schor, et altri Professori ${ }^{146}$. Die Kritik des Marchese Teodoli an dem zunächst ausgeführten Mittelstück ging von rein formalen Kriterien aus (zu große Figuren). Bolognas Brief vom 1. Oktober 1679 besagt zwar, dass der Marchese ihn drängte, ein neues (kleinteiligeres) Relief in Auftrag zu geben, doch ist damit noch längst nicht klar, wer für die Themenwahl verantwortlich war ${ }^{147}$.

Das ,Jüngste Gericht“ fügt sich auf besonders raffinierte Weise in das Gesamtkonzept des Schrankes ein. Das Relief, das in der Miniatur-Architektur des Kabinettschranks die Position des Portals einnimmt, thematisiert ein "Schwellenerlebnis', die Auferstehung der Toten zum Ewigen Leben, den Übertritt aus der irdischen Welt in das Reich Gottes. Gut und Böse scheiden sich - das kann religiös bzw. moralisch ausgedeutet werden (etwa im Hinblick auf die anderen Reliefs, die sowohl antike als auch christliche Tugendexempla vorführen und zum Kampf für den rechten Glauben aufrufen ${ }^{148}$ ), das hat aber auch eine ästhetische Komponente, denn der Begriff giudizio, den das Relief aufruft, bezieht sich im Italienischen nicht nur auf das ,Jüngste Gericht“ (L'Ultimo Giudizio), sondern auch auf ästhetisches Urteilsvermögen ${ }^{149}$. Dies wird $u$. a. genau in jenem Brief deutlich, mit dem die Gebrüder Stainhart ihrem Auftraggeber die Fertigstellung der Reliefs mitteilen, ist dort doch von dem purgatissimo

144 Philipp Schors künstlerisch wesentlich bedeutenderer Vater Johann Paul scheidet als potentieller Entwerfer ebenfalls aus, weil er bereits am 13. März 1674 verstorben war, ziemlich genau ein Jahr vor Beginn der Arbeiten am studiolo d'avorio: vgl. Dokument 1 und Werkner, Johannes Paul Schor (wie in Anm. 21), 28, Anm. 107.

${ }^{145}$ Siehe oben Anm. 43 und Dokument 14.

${ }^{146}$ Dokument 14.

${ }^{147}$ Dokument 10.

${ }^{148}$ Siehe oben Abschnitt II.

${ }^{149}$ L. Grassi-M. PePe, Dizionario della critica d'arte I. Torino 1978, 218. 
giuditio Lorenzo Onofrio Colonnas die Rede ${ }^{150}$. Die in Elfenbein reproduzierten Kunstwerke spiegeln idealiter den Geschmack des Fürsten, sein giudizio, d. h. seine Fähigkeit, zwischen gut und schlecht zu unterscheiden ${ }^{151}$. Insofern ist das Thema des Mittelreliefs überaus geschickt gewählt, da im Begriff des giudizio die verschiedenen Subthemen und Funktionen des Kunstobjekts zusammenfallen.

Michelangelo, von Vasari als der größte, der „göttliche“ Künstler gepriesen, nimmt mit seinem „Jüngsten Gericht“ in der durch sakrale Würdeformeln nobilitierten Architektur des ,Kunstschreins' programmatisch das Zentrum ein. Berninis Verehrung für Michelangelo ist hinlänglich bekannt; wieder und wieder ließ er sich von dessen Werken inspirieren und versuchte sie zu übertreffen ${ }^{152}$. Der paragone, der Wettstreit zwischen den einzelnen Künsten, aber auch zwischen einzelnen Künstlern, besaß fundamentale Bedeutung für Berninis Schaffen ${ }^{153}$. Ohne das seit der Renaissance in Künstlerkreisen weit verbreitete Konzept des paragone ${ }^{154}$ wäre auch der Colonna'sche Kunstschrank nicht denkbar, geht es doch hier um das Wetteifern der Skulptur mit der Malerei, um die Nachbildung zweidimensionaler Werke in der dreidimensionalen Kunst des Reliefs. Den Elfenbeinschnitzereien fehlt die Farbe, die Lebhaftigkeit und Ausdruckskraft der Malerei, doch sie erzeugen Bewunderung durch die Bewältigung höchster technischer Schwierigkeiten. Auch wenn Michelangelos „Jüngstes Gericht“ als künstlerische invenzione unerreicht bleibt, verdient die Leistung höchsten Respekt, die figurenreiche Komposition, welche die gesamte Stirnwand der Sixtinischen Kapelle einnimmt, auf wenigen Dezimetern wiedergegeben zu haben. Auf Michelangelos monumentale Figuren, die gerade wegen ihrer, skulpturalen

${ }^{150}$ Dokument 13.

151 De facto verließ sich Lorenzo Onofrio Colonna zumindest teilweise auch auf die Kennerschaft seiner Berater, wie aus Dokument 14 hervorgeht.

${ }^{152}$ C. D’Onofrio, Roma vista da Roma. Roma 1967, 172-187; C. Thoenes, Bernini architetto tra Palladio e Michelangelo, in: Gian Lorenzo Bernini Architetto e l'architettura europea del Sei-Settcento I, hrsg. von G. Spagnesi-M. Fagiolo. Firenze 1983, 105-134; R. Premmesberger, Themes from Art Theory in the Early Works of Bernini, in: Gianlorenzo Bernini. New Aspects of His Art and Thought, hrsg. von I. Lavin. University Park-London 1985, 1-24, hier 6f.; T. Montanari, Gian Lorenzo Bernini e Sforza Pallavicino. Prospettiva 87/88 (luglio-ottobre 1997), 42-68, hier 58f.; STRUnck (wie in Anm. 136).

153 Premesberger (wie in Anm. 152).

154 Grundlegend hierzu L. Mendelsohn, Paragoni. Benedetto Varchi's Due Lezzioni and Cinquecento Art Theory. Ann Arbor 1982. 
Qualitäten gerühmt wurden ${ }^{155}$, antworten die Miniaturen des Elfenbeinschnitzers, der die ,skulpturale Malerei des Bildhauers Michelangelo in das Medium der Skulptur ,zurückübersetzt".

In ogni tempo e occasione dava fuori concetti nobili, motti acuti e grazie spiritosissime, wusste Baldinucci über Bernini zu berichten, und Sforza Pallavicino bezeichnete den Künstler als non men potente nel parlare che nel figurare ${ }^{156}$. Nicht minder schmeichelhaft äußerte sich Charles Perrault, der ansonsten mit dem Italiener auf Kriegsfuß stand: „Il avoit l'esprit vif et brillant et un grand talent à se faire valoir; beau parleur, tout plein de sentences, de paraboles, d'historiettes et de bons mots dont il se servoit dans la plupart de ses réponses, dédaignant de répondre simplement à ce qu'on lui demandoit"157. Chantelous Aufzeichnungen über Berninis Frankreichreise vermitteln ein lebhaftes Bild von dessen Neigung zum geistreichen Spiel mit Begriffen (concettismo): „Many passages in Chantelou's diary show that, in a typical Seicento spirit, Bernini's mind was much occupied with conceits - from the quick emotive response in the course of conversation, the pointed play with words, and the pun, to the intellectual penetration of a sculptural theme. Apart from his exceptional brilliance, Bernini may have shared all this with other artists of his time. Yet for him, in contrast to many of them, the concetto never was a cleverly contrived embroidery, but formed an intrinsic part of his work" 158 . Der Gedanke, den Colonna'schen Kunstschrank gewissermaßen unter das facettenreiche Motto giudizio zu stellen, wäre im Sinne Wittkowers wohl eine nachträglich hinzugefügte „embroidery“. Gibt es aber auch einen concetto, der als „intrinsic part" bzw. grundlegende Idee des Werks gelten kann?

Mit großer Wahrscheinlichkeit war der Kabinettschrank von Anfang an für den westlichen Anraum der Galerie bestimmt, in dem er schließlich nach Vollendung derselben Aufstellung fand ${ }^{159}$. Dieser zuvor eigenständi-

${ }^{155}$ G. VASARI, Le vite de' più eccellenti pittori scultori ed architettori scritte da Giorgio Vasari pittore aretino con nuove annotazioni e commenti di Gaetano Milanesi. Firenze 1906, Reprint: Firenze 1981, VII, $185 \mathrm{f}$.

156 Zitiert bei Montanari (wie in Anm. 152), 61.

${ }^{157}$ C. Perrault, Mémoires de ma vie. Paris 1993, 158.

${ }^{158}$ R. WIтtKower, The Vicissitudes of a Dynastic Monument: Bernini's Equestrian Statue of Louis XIV, in: De Artibus Opuscula XL. Essays in Honor of Erwin Panofsky, hrsg. von M. MeIss. New York 1961, I, 497-531, hier 502.

159 Wie in Abschnitt II erläutert, passt das ,glaubenskriegerische‘ Bildprogramm des Kabinettschranks hervorragend zur ähnlich gelagerten Thematik der Galerie. Ferner macht auch der Umstand, dass sechs Reliefs Fresken der Florentiner „Sala di Venere" kopieren, eine Bestimmung des Schrankes für den westlichen Anraum 


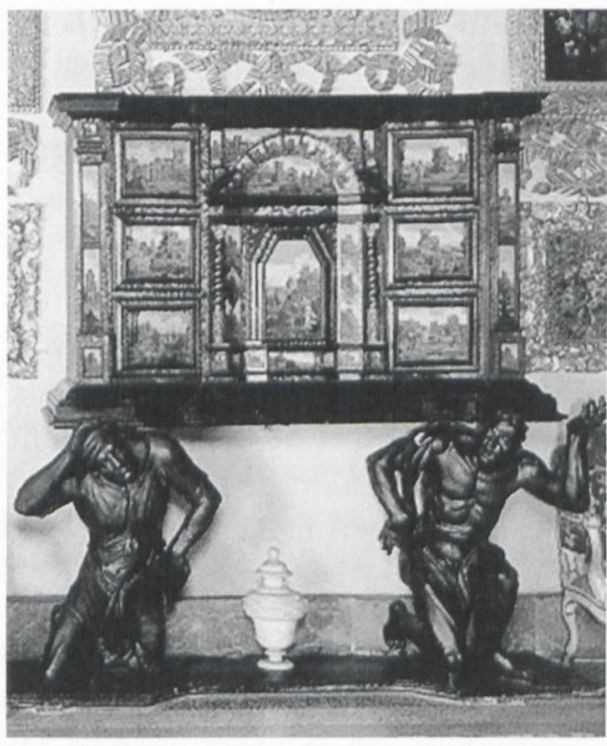

Abb. 18: Isola Bella, Palazzo Borromeo, Kunstschrank in der „Sala del Trono”

ge Saal wurde überhaupt erst durch Berninis innovatives Raumkonzept in die Galleria Colonna einbezogen und 1675 mittels eines großen säulengestützten Durchgangs mit dem ursprünglichen Galerieraum verbunden (Abb. 1) $)^{160}$. Infolgedessen brauchte jener Bereich eine neue, auf die Ausstattung der Galerie abgestimmte Dekoration. Der ebenfalls 1675 begonnene Kabinettschrank, in dessen Reliefs Skulptur und Malerei wetteifern, fügt sich perfekt in ein Ambiente ein, das sowohl durch monumentale Fresken als auch durch antike Statuen beherrscht wird. Indem die Elfenbeinschnitzereien Meisterwerke des 16. und 17. Jahrhunderts nachbilden, etablieren sie einen kunsthistorischen Kanon, der Geschmack bzw. giudizio des Auftraggebers spiegelt, und verweisen auf ein zentrales Thema des kunsttheoretischen Diskurses, den paragone. Darüber hinaus holen die Reliefs Kunstwerke in die Galerie, die dort realiter nicht ausgestellt werden können. Die augenzwinkernden Verweise auf Monumentalskulpturen Berninis verstärken den zitathaften Charakter jenes ,Musée imaginaire‘. In Analogie zum Konzept des ,Bildes im Bild' oder des ,Theaters auf dem Theater ${ }^{\prime 161}$, das von der barocken Lust an der spielerischen Potenzierung von Realitätsebenen zeugt, ist der Colonna'sche Kabinettschrank letztlich eine ,Galerie in der Galerie“ - eine pfiffige Idee, die schon bald imitiert wurde (Abb. 18) ${ }^{162}$. Auch wenn Berninis Autorschaft nicht

der Galleria Colonna wahrscheinlich, der ebenfalls eine „Sala di Venere“ war. 1675 ließ sich natürlich nicht absehen, dass sich die Bau- und Ausstattungsarbeiten in der Galerie schließlich bis zum Jahr 1700 hinziehen würden. Den empfindlichen Schrank vor Abschluss der Arbeiten in der Galerie aufzustellen, wäre unvernünftig gewesen.

160 Siehe oben Anm. 115.

161 Die Idee der commedia in commedia spielte übrigens auch in Berninis Theaterschaffen eine Rolle: I. Lavin, Bernini \& l'unità delle arti visive. Roma 1980, 163.

${ }^{162}$ Ein heute in der "Sala del Trono" des Palazzo Borromeo auf der Isola Bella befindlicher Kunstschrank (Abb. 18) ähnelt nicht nur durch seinen Untersatz, 
mit absoluter Sicherheit zu beweisen ist, sprechen dokumentarische Belege, motivische Übernahmen und konzeptionelle Bezüge zu seinem Schaffen doch deutlich für seine Beteiligung an diesem ungewöhnlichen Entwurf, der Großes im Kleinen ausdrückt.

\section{ANHANG: Dokumente (Auswahl) ${ }^{163}$}

Dokument 1: Rechnung von Giacomo Herman Ebenista a S. Ignatio ab 1. Februar 1675 (in I. A. 60)

24. April 1675: ho segato un pezzo d'avolio in 4 fette grosse, et hò spianato e drizzato et ho fatto giusto in squadro a tre giuli l'uno servivano per far intagliare il basso rilevo (scudi 1:20)

Più ho segato da vinti pezzi d'avolio e spianato e drizzato, e fatto in squatro giusto a tre giuli l'uno (scudi 6:00)

Più ho fatto una cornicetta di pera una modellatura bella serviva per un pezzo di questo basso rilievo d'avolio (scudi 0:80)

Più ho dato più volte pezzi grandi di pera al scultore per far figurette segato a proposito (scudi 1:20) [dieser Rechnungsposten wurde nachträglich durchgestrichen]

10. Juli 1675: ho fatto una cornice di pero longa per un disegno di architettura in carta pecora con suo anello d'argento (scudi 1:20)

3. Januar 1676: Ho fatto numero 4 cornice [sic] d'ebano di dentro e di fuora con il cristallo inanzi al basso rilievo di avolio e giustato l'ebano sopra l'intaglio d'avolio per far patente al cristallo (zusammen scudi $6: 40$ )

26. April 1677: Più ho fatto una tavola longa palmi ondeci incirca di dui pezzi con sue strettore per stringerle insieme per far un disegno sopra del cavaliere Fontana (scudi $6: 50)$

Più due cornice [sic] di dentro e di fora, con il cristallo avanti il basso rilevo di avolio ... (scudi $2: 60$ )

Più per le sudette due cornice [sic] ho fatto e giustato otto fresci di avolio con otto cantoni sopra sopra [sic] le ovate per intagliare come ancora quaranta otto pezzi d'avolio

sondern auch durch sein ,enzyklopädisches' Programm (in diesem Fall eine Galerie verschiedener antiker Monumente) dem Colonna-Prunkmöbel. Da Carlo Fontana 1686 und 1687 für den Palazzo Borromeo Entwürfe lieferte, ist die Нypothese verlockend, dass er auch die Variation auf den Colonna'schen Kabinettschrank angeregt haben könnte. Dagegen spricht jedoch nicht nur das Ankaufsjahr 1784, sondern auch die Zeichnung, die Fontana von eben jener „Sala di Trono" anfertigte und die an der Stelle des genannten Kunstmöbels noch einen wesentlich altmodischeren Schrank zeigt. González-Palacios, Il Tempio (wie in Anm. 4), II, 32, Abb. 29; vgl. Le Isole Borromeo e la Rocea di Angera. Guida storico-artistica. Cinisello Balsamo 2000, 26-28.

${ }^{163}$ Die im Folgenden abgedruckten Dokumente befinden sich - ebenso wie die in den Fußnoten zitierten - im Archivio Colonna (Subiaco) - mit Ausnahme von Dokument 5 und 15, die nach der Edition von Pollak (wie in Anm. 4) zitiert werden, da sich die Originale unter der von ihm angegebenen Signatur nicht mehr auffinden lassen. Außer in den beiden genannten Fällen wurden Abkürzungen im Interesse der besseren Lesbarkeit bei der Transkription stets aufgelöst. 
segato, drizzato spianato per intagliar servono intorno alli bassi rilevi d'avolio importa senza l'avolio sette scudi e sei giuli (scudi 7:60).

Dokument 2: Giuseppe Venantij an Lorenzo Onofrio Colonna, 15. September 1678 (Miscellanea storica II. A. 57, Nr. 1) ) $^{164}$

... Li todeschi come ho già scritto a Vostra Eccellenza hanno terminato il lavoro delli mori, et hora stanno in fine delli fregi d'avorio per l'altro studiolo, in quest'altra settimana principiaranno il pezzo maggiore e più riguardevole, che va nel mezzo, dove dicono consumaranno da tre mesi, e poi ci sono due altri pezzi di quelli ordinarij, e gl'ornamenti piramidali che vanno sopra il detto studiolo, dove dicono havere a travagliare tre altri mesi. Il Cavalier Fontana è fuori di Roma subito che tornerà farò che gli limiti il tempo per quanto sarà possibile; intanto vado somministrandoli l'avorio, et acciò non perdano un momento di tempo, essendosi raccomandati per una lettera di raccommandatione in Napoli li ho promosso [sic; gemeint ist promesso?] volerne supplicare Vostra Eccellenza ogni volta, che mi fanno conoscere la loro puntualità in servire celeramente l'Eccellenza Vostra, che è quanto m'occorre di significarle per hora mentre humilmente me l'inchino ... .

Dokument 3: Maurizio Bologna an Lorenzo Onofrio Colonna, 17. September 1678 (Carteggio L. O. Colonna 1678, camicia 68)

... Parlarò col Signor Marchese Teodoli affinche habbia la bontà di far perfettionare il piede dello studiolo col suo buon gusto. ... .

Dokument 4: Maurizio Bologna an Lorenzo Onofrio Colonna, 1. Oktober 1678 (Carteggio L. O. Colonna 1678, camicia 68)

... Ho parlato col Signor Marchese Teodoli in nome di Vostra Eccellenza acciò col suo buon gusto si perfettioni il piede dello studiolo pretioso, che dice farà far subito che haverà un poco di tempo .... .

Dokument 5: Carlo Fontana an Lorenzo Onofrio Colonna, 18. Februar $1679^{165}$

... Per desimere l'Ecc. ${ }^{z a} \mathrm{~V}$. di questa cotidiana spesa delli scultori D'avorio, con il Sig. D. Mauritio si resto dare fori ad'altri simili professori il finimento, con patto si del Tempo come del prezzo, e fù messo quasi in pratica, mà perche sono tanto pochi che fra di loro si seppe subito, al quale mi mancorno per rispetto fra di loro, però dicono $2 .^{\circ}$ questa mattina fra le altre che sono stato alla sollecitudine, che per Pasqua oninamente daranno finito il pezzo di mezzo, che riescie ottimo, si che resta solo li troffey, li quali si è detto farli di metallo per levare la Cagione e la spesa che doppo li daranno a fare a chi farà meglio partito, che già li medesimi faranno il lavoro non Essendovi sol rispetto licenziato che haverà $V$. Ecc. ${ }^{a}$ li d. ${ }^{i}$ tanto più che quello riguarda al Concerto di tutti li bassi rilievi li habbiamo tutti di una qualità e mano, che sarebbe stato difficile havere simili accordo della maniera, Essendo donque li troffej di altra spetia e qualità di lavoro che ogni altro

${ }^{164}$ In leicht abweichender Transkription publiziert von PoLLAK (wie in Anm. 4), 16. Pollak gibt das Datum 17. September 1678 an, das sich auf der Rückseite des Schriftstücks von anderer Hand vermerkt findet. Das am Ende des Briefes angegebene Datum lautet jedoch 15. September 1678 (nicht 25. September wie bei Gozzano, wie in Anm. 250).

${ }^{165}$ Zitiert nach Pollak (wie in Anm. 4), 17; vgl. Anm. 163. 
Scultore li puol fare non havendo che fare con il $d .{ }^{\circ}$ Concerto, del resto qui si hà tutto il principale per potere mettere assieme l'opra che per Collocare à suo loco li d. ${ }^{i}$ Bassi rilievi e per non perdere le spetie [? spese] e dissegni, già destribuiti, stimarei quando l'Ecc. ${ }^{a}$ Sua l'aprovasse fare solo l'ossatura quando non voglia perfettionare l'opra che di questo sene attendera li bramati Comandamenti pregando l'Ecc. ${ }^{z a} V^{a}$ di simili gratie che mene fece favore quà in Roma in servitio dell'Ecc. ${ }^{m a}$ Casa mentre resto con fare Dev. ${ }^{m a}$ e Prof. ${ }^{\text {ma }}$ Riverenza ....

Dokument 6: Maurizio Bologna an Lorenzo Onofrio Colonna, 4. März 1679 (Carteggio L. O. Colonna 1679, camicia 238)

... Gl'Intagliatori todeschi hanno per quattro mesi continui lavorato nel Pezzo grande dello studiolo d'avorio, et havendomelo portato vi ho scoperto molti difetti notabili onde gli ho forzati a raccomodarlo e finirlo a perfettione a spese loro, mentre l'havevano tirato giù alla peggio come ha riconosciuto ancora il Cavalier Fontana, e benche siano stati licentiati gli ho fatti obligare a fare un altro pezzo piccolo che mancava per compimento di tutta l'opera havendo il Maestro di Casa stabilito di pagarlo a parte con far riconoscere l'opera per evitare la spesa acciò non si trattengano in quest'altro Pezzo altri quattro mesi, e cosi lavoraranno più presto, e con più attentione senza defraudare il tempo che impiegavano in lavorar per altri ... .

Dokument 7: Maurizio Bologna an Lorenzo Onofrio Colonna, 28. April 1679 (Carteggio L. O. Colonna 1679, camicia 238)

... Ho reso la lettera al Cavalier Fontana, e siamo restati di unirsi Domenica col Signor Marchese Teodoli, acciò col suo buon gusto possa incontrarsi quello di Vostra Eccellenza in ordine alla fabrica dello studiolo d'avorio, e si procurarà di far travagliare li medesimi Todeschi se vorranno trattenersi più in Roma, essendosi il migliore partito per Napoli senza dire a Dio, e subito al suo ritorno del quale m'assicura il fratello restato in Casa si farà che seguitino il lavoro con la minor spesa possibile... .

Dokument 8: Maurizio Bologna an Lorenzo Onofrio Colonna, 14. Mai 1679 (Carteggio L. O. Colonna 1679, camicia 238)

... Il Cavaliere Fontana scrive a Vostra Eccellenza quanto si è risoluto con il Signor Marchese Teodoli per dar buon fine all'opera dello studiolo d'avorio, e solo s'attende il ritorno dello scultore tedesco, che si aspetta di Napoli di giorno in giorno per finire quello che manca di operare, e casoche questo non ritorni si è parlato gia con un Suezzese [sic] huomo assai prattico, e di buon disegno nella scultura, dal quale Vostra Eccellenza pigliò un non sò che per portare in Spagna, e credo che non farà male ... .

Dokument 9: Maurizio Bologna an Lorenzo Onofrio Colonna, 28. Mai 1679 (Carteggio L. O. Colonna 1679, camicia 238)

... Che è quanto devo rappresentare a Vostra Eccellenza; e di esser ritornato di Napoli il Tedesco scultore.... .

Dokument 10: Maurizio Bologna an Lorenzo Onofrio Colonna, 1. Oktober 1679 (Carteggio L. O. Colonna 1679, camicia 238)

... Il Signor Ambasciator di Spagna ha voluto favorire questo Palazzo con mandarmi a dire che lo voleva vedere, havendogli fatto osservare il tutto, et a quest'effetto chiamai Filippo Schor acciò potesse dargli la cognitione di tutti li pittori di che hebbe gran gusto, 
e particolarmente stima assai alcuni de'quali disse il nome dell'Artefice perche Filippo non lo sapeva, domandandomi della Salute di Vostra Eccellenza, e facendoli riverenza.

Lo Studiolo gioiellato li parve di meraviglia, e si lui stima che sarà quello d'avorio il quale vado con la direttione, e parere del Signor Marchese Teodoli io governandomi per portarlo a perfettione mentre detto Signor Marchese insinua che il Cavalier Fontana nel pezzo grande che ha fatto fare per mettere in mezzo non sia proportionato alli altri lavori fatti in tutto lo studiolo per essere di figure grandi come io una volta significai a Vostra Eccellenza che non mi piaceva; Si che hora mi spinge a farne un altro di nuovo che comincieranno quanto prima $7 i$ Tedeschi e questo sarà senza dispendio veruno perche io ho avanzato tanto con haverli levati di rollo che con questo sparambio pagherò quest'ultima loro fatica ....

Dokument 11: Maurizio Bologna an Lorenzo Onofrio Colonna, 11. Novembre 1679 (Carteggio L. O. Colonna 1679, camicia 238)

... Li giorni passati fù nel Quartier di Spagna carcerato uno di ordine del Papa ..., e nello stesso giorno accadè, che uno delli nostri scultori tedeschi hebbe rissa con un suo Paesano nella Piazza del medesimo Signore Ambasciatore e feritolo à morte, come seguita, venne subito a refuggiarsi in Casa, che saputo da me lo tenni secreto, e stimando bene levarlo di qui, l'ho fatto trasbaltare in Napoli la settimana passata ... .

Dokument 12: Maurizio Bologna an Lorenzo Onofrio Colonna, 18. Februar 1680 (Carteggio L. O. Colonna 1680, camicia 59)

... Restò Vostra Eccellenza servita mesi sono ordinarmi che mi governassi con il parere, e buon gusto del Signor Marchese Teodoli per perfettionare il nuovo piede dello studiolo gioiellato, et havendo cosi eseguito prontamente, non ho mai contradetto punto dal suo sentimento, havendo di persona il mede [si] mo del continuo assistito sopra gli operarij piu, e più volte, et essendo di già venuto in fine il piede, che ha volsuto che fosse tutto di ebano, conforme al disegno che Vostra Eccellenza lassò, però nel tempo di accomodarci li mori, che li scultori tedeschi lavorono non è stato possibile accomodarveli conforme al disegno; si che è stato necessario di nuovo a guastarli et aggiustarli con gran fatica, e travaglio con il parere di Filippo Schor, et altri periti in quest'arte, et in fine per la Dio gratia si è arrivato alla perfettione, e spero, che Vostra Eccellenza ne resterà sodisfatta benche it Signor Teodoli non ha havuto riguardo a spesa accio riuscisse compita l'opera ... .

Dokument 13: Domenico e Francesco Stainardi Tedeschi an Lorenzo Onofrio Colonna, 6. Juli 1680 (Carteggio L. O. Colonna 1680, camicia 133)

Illustrissimo et Eccellentissimo Signore Padrone Colendissimo

L'ardire, che pigliamo di comparire avanti a Vostra Eccellenza con queste poche righe, non da altro proviene, che da un impulso d'una divotissima osservanza, la quale ci obbliga con ossequij di riverenza a darle parte come gia habbiamo havuto l'honore d'haver finito tutta l'opera dello studiolo; E perche l'Eccellenza Sua come Signore, che con l'occhio del suo rettissimo, e purgatissimo giuditio avanti la partenza in vedere alcuni pezzi già fatti ne diede segno di gradimento, cosi speriamo, che nel ritorno, che pregando Iddio che esaudisca li nostri voti ad esser presto, Vostra Eccellenza incontrerà le medesime sodisfattioni, mentre habbiamo fatto l'ultimo sforzo in operare con quella attentione, che è propria d'un servitore che ambisce di servire un Signore di tanto merito. Dove hora fatti arditi rinoviamo a Vostra Eccellenza la benignissima intentione, che favori di darci a non tralasciar di continuar il lavoro, che finito ci haverebbe fatto sperimentare quanto grande 
fosse l'animo generoso di Vostra Eccellenza con mandarci consolato con qualche buona riconoscenza, et ogni volta, che noi habbiamo l'honore di meritarlo ci sarebbe singolarissima fortuna partir dalla Casa di Vostra Eccellenza rimunerato di simil favore tanto più per esserci ancora di gran sollievo nell'occasione prossima, la quale ci astringe a partire alla volta della Patria, però ogni volta, che Vostra Eccellenza non ordina diversamente a fermarci per qualche suo comandamento che tanto ci pregiamo d'esequire, e la preghiamo istantemente che dovunque ci troviamo, e che Vostra Eccellenza havesse accaro [= a caro?] l'opera nostra basta un sol cenno, che sarà spione a renderci velocissimi a venirla a servire; et in tanto le facciamo profondissima riverenza. Roma 6 luglio 1680

Humitissimi e divotissimi Servitori obbligatissimi

Domenico $\}$

Francesco $\}$ Stainardi tedeschi

Dokument 14: Maurizio Bologna an Lorenzo Onofrio Colonna, 11. Juli 1680 (Carteggio L. O. Colonna 1680 , camicia 59)

... Per gratia di Dio ho già terminato l'opera dello studiolo d'avorio, havendo licentiato li scultori tedeschi co' quali ho havuto gran patienza a segno che li ho fatti lavorare sino in camera mia, et in quanto all'historie da farsi ne bassi rilievi mi son governato con $i$ pareri del Signor Marchese Teodoli, Cavalier Bernino, Filippo Schor, et altri Professori, mentre il Fontana dal principio errò in alcuni pezzi e particolarmente nel Grande. Il pezzo grande è il giuditio Universale di Michel Angelo, la strage degl'Innocenti del Rubens, la Resurretione del Signore parimente di Michel Angelo, la Crocifissione del Signore di Lanfranco, et altri pezzi che sono al numero di sei che restorno da farsi quando Vostra Eccellenza parti mi dicano tutti che siano ben fatti, e l'ho pagati per metà meno di quello che mi sono stati stimati dalli sopradetti e volendo questi poveretti ritornarsene a loro paesi, desiderarebbero, che Vostra Eccellenza li facesse gratia di darli qualche regalo per aiuto del loro viaggio, mentre dicano che cosi Vostra Eccellenza li promise, di che ne starò attendendo li ordini .... .

Dokument 15: Carlo Fontana an Lorenzo Onofrio Colonna, 12. Juli $1680^{166}$

... Si è messo insieme sopra la tavola dove fù disegnato il studiolo tutti li pezzi d'avorio tanto li bassi rilievi fogliami, Trofei, Arabeschi, et altro, e per quello riguarda alli scultori Todeschi hanno dato fine con molta loro lode in havere terminato il remanente doppo partito l'Ecc. ${ }^{a} V^{\text {ra }}$ con magior maestria, tanto più che il pezzo di mezzo che vi ̀̀ scolpito il giuditio di Michelangelo quale per la numerosità delle figure, e sito sono riuscite di tanto bell'accordo, e corrispondenza con gl'altri bassi rilievi piccoli di modo tale si per l'Armonia come per l'esquisitezza del lavoro, è detto pezzo inestimabile a segno tale è impossibile trovarne il compagno perche pare sia stato fatto dal proprio Michelangelo. Si è anche con ordine del S.r D. Mavoritio, e Sig.' marchese Teodoli risoluto, che l'Ebanista cominci a comporre, et inossare il studiolo acciò possi situare per la sicurezza di detti bassi rilievi, che perciò si darà principio quanto prima, e mi è parso bene darne aviso a $V^{r a}$ Ecc. ${ }^{a a}$ del buon esito che hà hauto quest'opera cosi reggia mentre con Humilissima e profondissima Riverenza m'inchino con quell'ossequio che richiede l'Humiltà mia per suplicar l'Ecc. ${ }^{z a} V^{r a}$ de continui honori e comandamenti ... .

${ }^{166}$ Zitiert nach PollaK (wie in Anm. 4), 17f; vgl. Anm. 163. 
Dokument 16: Maurizio Bologna an Lorenzo Onofrio Colonna, 10. Novembre 1680 (Carteggio L. O. Colonna 1680, camicia 59)

... Per gratia di Dio mi vedo già libero con haver terminato il piede dello studiolo gioiellato, e postolo sù con haverlo fatto pulire, e raggiustare in modo che credo sarà di gusto di Vostra Eccellenza; ancorche il Signor Marchese Teodoli mi habbi abbandonato per la sua podagra, e assenza da Roma, che assicuro Vostra Eccellenza mi è stato un purgatorio a combattere con tanti artisti ... .

Dokument 17: Maurizio Bologna an Lorenzo Onofrio Colonna, 2. Februar 1681 (Carteggio L. O. Colonna 1681, camicia 16)

... Vado sollecitando con premura l'Ebanista a lavorare l'ossatura dello studiolo d'avorio, che già ha cominciato, e mi dice vorrà di tempo un anno per finirlo benchè ci tenga tre homini di continuo intorno, et Io sempre lo vedo col Cavalier Fontana ... .

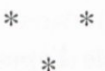

\section{ABBILDUNGSNACHWEIS}

Abb. 1, 3:

Bibliotheca Hertziana

Abb. 2, 16:

Anderson

Abb. 4:

moscioni

Abb. 5, 13:

Amministrazione Colonna

Abb. 6, 7, 8, 10, 11, 12, 18: Autorin

Abb. 9:

Arte Fotografica

Abb. 14, 15, 17:

Alinari 